\title{
Do Words Hurt More Than Actions? The Impact of Trade Tensions on Financial Markets
}

\author{
Massimo Ferrari ${ }^{1}$, Frederik $\mathrm{Kurcz}^{2}$ and Maria Sole \\ Pagliari $^{3}$
}

January 2021, WP \#802

\begin{abstract}
In this paper, we apply textual analysis and machine learning algorithms to construct an index capturing trade tensions between US and China. Our indicator matches well-known events in the US-China trade dispute and is exogenous to the developments on global financial markets. By means of local projection methods, we show that US markets are largely unaffected by rising trade tensions, with the exception of those firms that are more exposed to China, while the same shock negatively affects stock market indices in EMEs and China. Higher trade tensions also entail: i) an appreciation of the US dollar; ii) a depreciation of EMEs currencies; iii) muted changes in safe haven currencies; iv) portfolio re-balancing between stocks and bonds in the EMEs. We also show that trade tensions account for around $15 \%$ of the variance of Chinese stocks while their contribution is muted for US markets. These findings suggest that the US-China trade tensions are interpreted as a negative demand shock for the Chinese economy rather than as a global risk shock.
\end{abstract}

Keywords: Trade Shocks; Machine Learning; Stock Indexes; Exchange Rates

JEL classification : D53; E44; F13; F14; C55

We would like to thank Michele Ca' Zorzi, Georgios Georgiadis, Johannes Gräb, Maurizio Habib, Arnaud Mehl, Livio Stracca, Fabrizio Venditti, seminar participants at the BdI-FED Board joint conference and an anonymous referee for valuable comments. All errors are our own.

${ }^{1}$ European Central Bank, massimo.ferrari1@ecb.europa.eu.

${ }^{2}$ Berlin School of Economics, frederik.kurcz@gmail.com.

${ }^{3}$ Banque de France, maria-sole.pagliari@banque-france.fr.

Working Papers reflect the opinions of the authors and do not necessarily express the views of the Banque de France and of the European Central Bank. This document is available on publications.banque-france.fr/en 


\section{NON-TECHNICAL SUMMARY}

Since the beginning of the 2016 US electoral campaign, trade deficits, trade agreements, exchange rate management and tariffs imposition have been at the core of the economic policy debate. In the subsequent years there has been an escalation in trade tensions between US and China, a period that is often referred to as the Sino-American «trade war», whereby both countries have implemented bilateral tariffs aimed at harming key sectors of the opponent's economy, in an attempt to force it into a more favorable trade treaty.

As to the consequences of trade tensions for the global economy, academics and policy makers are still struggling to quantify the extent to which such tensions have spoken to the global economic slowdown of 2019. In this regard, the dominant view argues that "the weakness in growth is driven by a sharp deterioration in manufacturing activity and global trade, with higher tariffs and prolonged trade policy uncertainty damaging investment and demand for capital goods" (Gopinath (2019)). There are several channels through which tariffs can hamper global economic activity. For example, higher tariffs increase the price of imported goods, shifting demand towards domestic production and reducing revenues for foreign producers. Such losses may be further amplified by second-round effects through the global value chain (i.e. production-reducing exporters in turn decrease their demand for intermediate goods) which can eventually feed back into the tax-imposing country. Another channel is related to risk: tariff threats might increase uncertainty around the profitability of investment projects, thus making them less appealing and leading to a delaying of investments with detrimental on the economic outlook. There is not however a strong consensus on which of these channel prevails or on the quantification of the effects of rising trade tensions. For example, general equilibrium models based on trade elasticities produce sizable effects of trade barriers only when assuming large shocks. Recent contributions have also suggested that these results might be driven by significant asymmetries in the response to tariffs (Furceri et al. (2018)), or by changes in exchange rate adjustments mechanism over the last decade (Eichengreen (2017)).

Against this backdrop, our paper proposes three innovative contributions to the existing literature. First, we construct a proxy for trade tensions shocks by adopting a novel approach, which is based on textual analysis. Specifically, we use a supervised machine learning algorithm to assess the relative "protectionism content" of a large set of announcements in the Sino-American "trade war". The time series of such scores provides a trade tension measure, which can be used to quantify their impact on the global economy. Second, we show that the constructed measure is exogenous to financial market developments (both domestic and global), thus supporting the main assumption that announcements have been largely unanticipated by markets. This result is indeed relevant as allows to use the indicator as a measure of unexpected trade-policy surprises. Finally, we use the index to assess the reaction of financial agents to an increase in trade tensions. We show that a trade tension shock leaves the US stock market almost unaffected, except for those companies heavily exposed to China, while also inducing a contraction of stock market indexes both in China and other emerging market economies (EMEs). Moreover, the same shock entails an appreciation in the US dollar, a broad depreciation in EMEs currencies, while safe heaven currencies remain almost unaffected. The absence of safe-haven effects seems to suggest that trade tension shocks are interpreted by international investors as a negative demand to Chinese production rather than as a global risk aversion shock, with the US dollar appreciation simply reflecting a trade re-balancing. This intuition is further reinforced by the results for fixed income markets. While, indeed, US long term yields do not react significantly to the shock, market participants in EMEs tend to substitute stocks with bonds, thus effectively re-balancing their portfolios. 


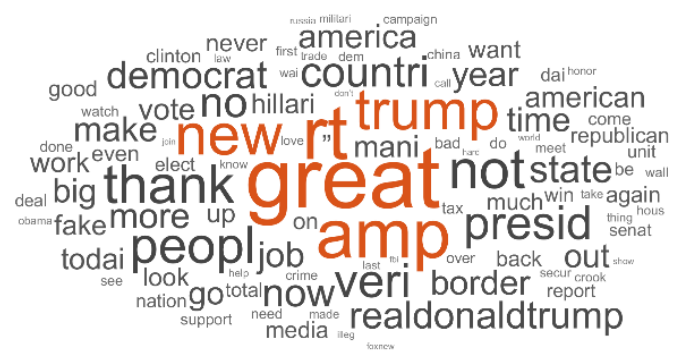

All tweets since January 2016

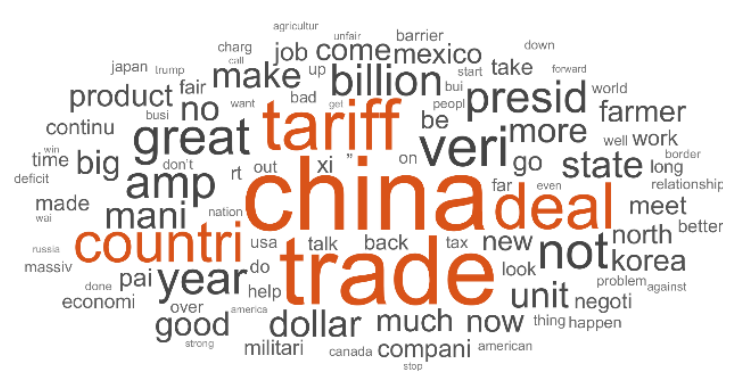

Tweets in the Bloomberg's trade war timeline

\title{
Les mots font-ils plus mal que les actes? L'impact des tensions commerciales sur les marchés financiers
}

\begin{abstract}
RÉSUMÉ
Dans cet article, nous appliquons des algorithmes d'analyse textuelle et d'apprentissage automatique pour construire un indice qui rend compte des tensions commerciales entre les États-Unis et la Chine. Notre indicateur correspond à des événements bien connus du conflit commercial entre les États-Unis et la Chine et est exogène par rapport à l'évolution des marchés financiers mondiaux. À l'aide de méthodes de projection locales, nous montrons que les marchés américains sont largement épargnés par l'augmentation des tensions commerciales, à l'exception des entreprises qui sont plus exposées à la Chine, tandis que le même choc affecte négativement les indices boursiers dans les marchés émergents et en Chine. Les tensions commerciales accrues entraînent également : i) une appréciation du dollar américain ; ii) une dépréciation des monnaies des marchés émergents; iii) des variations modérées des monnaies refuges ; iv) un rééquilibrage des portefeuilles entre les actions et les obligations dans les marchés émergents. Nous montrons également que les tensions commerciales représentent environ $15 \%$ de la variance des actions chinoises, alors que leur contribution est modérée pour les marchés américains. Ces résultats suggèrent que les tensions commerciales entre les États-Unis et la Chine sont interprétées comme un choc de demande négatif pour l'économie chinoise plutôt que comme un choc de risque mondial.
\end{abstract}

Mots-clés : chocs commerciaux ; apprentissage automatique ; indices boursiers ; taux de change

Les Documents de travail reflètent les idées personnelles de leurs auteurs et n'expriment pas nécessairement la position de la Banque de France et de la Banque Centrale Européenne. Ils sont disponibles sur publications.banque-france.fr 


\section{Introduction}

Since the beginning of the 2016 US electoral campaign, trade deficits, trade agreements, exchange rate management and tariffs imposition have been at the core of the economic policy debate $^{1}$. In the subsequent years there has been an escalation in trade tensions between US and China, a period that is often referred to as the Sino-American "trade war", whereby both countries have implemented bilateral tariffs aimed at harming key sectors of the opponent's economy, in an attempt to force it into a more favourable trade treaty. The barriers effectively implemented, however, are minor compared to those each contender threatened to raise (Figure 1). The US administration got to the point of suggesting it would withdraw from the WTO, should the organization not "shape up" to tackle alleged unfair trade practices by China ${ }^{2}$.

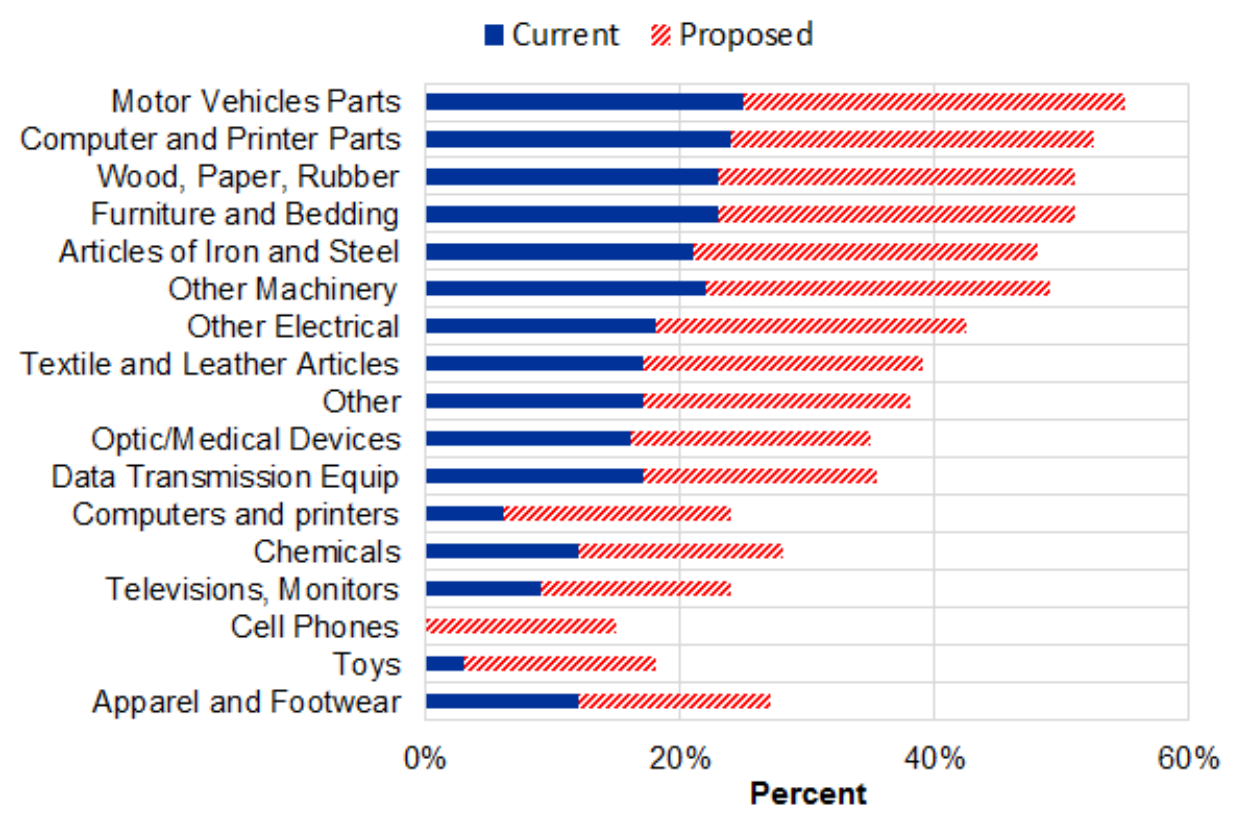

Figure 1: Current and proposed US tariffs against China by good category.

Source: Congressional Research Service (2019).

The "trade war" seems to have then entered a phase of armed truce, with the US and China involved in the definition of a "phase one deal", which is still ongoing at the time of redaction of this paper. As to the consequences of trade tensions for the global economy, academics and policy makers have in particular tried to quantify the extent to which such tensions have spoken to the global economic slowdown of 2019. In this regard, the dominant view argues that "the weakness in growth is driven by a sharp deterioration in manufacturing activity and global trade, with higher tariffs and prolonged trade policy uncertainty damaging investment and demand for capital goods" (Gopinath (2019)). Specifically, tariffs can hamper global economic activity via

\footnotetext{
${ }^{1}$ See for example the 2018 Charlevoix G7 Summit Communique.

${ }^{2}$ See "Donald Trump threatens to pull US out of the WTO", The Financial Times, 31 August 2018.
} 
two main channels. First, higher tariffs trigger direct effects through trade, as higher tariffs interfere with the optimal price equilibrium, thus giving rise to deadweight losses as per the Harberger triangle. Such losses are then amplified by second-round effects through the global value chain (i.e. production-reducing exporters in turn decrease their demand for intermediate goods) which can eventually feed back into the tax-imposing country (Meinen (2019)). The second channel is mainly related to risk: the mutual barrages of tariff threats between the US and China might have raised market participants' concerns about the profitability of investment projects, thus making them less appealing ${ }^{3}$. This in turn leads to further delay investments, with detrimental effects on both aggregate demand and (possibly) future output contractions stemming from productivity losses.

Our paper proposes three innovative contributions to the existing literature on trade tensions between the US and China. First, we construct a proxy for trade tensions shocks by adopting a novel approach, which makes use of the announcements regarding the US-China trade dispute on the US President Twitter $\left.{ }^{(}\right)$account to measure innovations in the history of Sino-American trade tensions that are exogenous to macroeconomic and financial developments. The new indicator is based on the "protectionism content" of each tweet. Specifically, we download all tweets from President Trump's Twitter ${ }^{\complement}$ account and we deploy textual analysis and machine learning techniques to assign a score quantifying the degree of protectionism to each tweet. The time series of such scores provides us with the trade tension measure, which we name Trade Tension Tweet Index (3T-Index).

Second, we show that the 3T-Index is exogenous to financial market developments (both domestic and global), which indicates that announcements have not been anticipated by markets. Finally, we use the 3T-Index to assess the reaction of financial agents to an increase in trade tensions. We show that a trade tension shock leaves the US stock market almost unaffected, except for those companies heavily exposed to China, while also inducing a contraction of stock market indexes both in China and other emerging market economies (EMEs). Moreover, the same shock entails an appreciation in the US dollar, a broad depreciation in EMEs currencies, while safe heaven currencies remain almost unaffected. The absence of safe-haven effects seems to suggest that trade tension shocks are interpreted by international investors as a negative demand to Chinese production rather than as a global risk aversion shock, with the US dollar appreciation simply reflecting a trade re-balancing. This intuition is further reinforced by the results for fixed income markets. While, indeed, US long term yields do not react significantly to the shock, market participants in EMEs tend to substitute stocks with bonds, thus effectively

\footnotetext{
${ }^{3}$ This is often referred to as the "confidence channel" (Gloe Dizioli and van Roye (2018)).
} 
re-balancing their portfolios. These results are reinforced by the analysis of the contribution of the 3T-Index to the forecast error variance decomposition (FEVD) of financial variables. We show that the index explains $10 \%$ to $15 \%$ of the volatility of EMEs financial markets while its contribution is muted for US stocks; the index also does not explain movements of safe have assets such as US 10-year yields or the Japanese yen.

Our results suggest that market participants have read trade-related surprises as real shocks to Chinese demand, rather than an increase in global risk.

\subsection{Related literature}

This paper is related to and builds on three main strands of literature: i) research assessing the macroeconomic implications of trade shocks; ii) research focusing on the role of uncertainty; iii) research applying machine learning and textual analysis techniques to economics.

\section{The macroeconomic implications of trade shocks}

The beginning of the so-called "trade war" between the US and China has brought about several contributions investigating the effects of rising protectionism. One strand of literature uses multi-country general equilibrium models to assess the implications of rising trade barriers. Berthou et al. (2018), for example, finds that a general increase of tariffs by $10 \%$ would contract global GDP by $2 \%$ on impact. Gloe Dizioli and van Roye (2018) reach similar conclusions under slightly different assumptions. Ossa (2014), instead, develops a multi-country model featuring traditional, new trade, and political economy motives for protections. In that setting, a breakdown of international trade policy cooperation generates welfare losses of $2.9 \%$ on average, while gains from future trade agreements improve welfare by $0.5 \%$ on average. Moving to empirical approaches, Barattieri et al. (2018) use country-level VARs to show that tariffs act as a supply shock for the imposing country with limited effects on the trade balance. Other papers, such as Feenstra et al. (2019), Autor et al. (2016), Feenstra and Sasahara (2018) and Acemoglu et al. (2016), analyse sector-level data and find that reducing import barriers have positive spillovers to domestic sectors, which in turn leads to an expansion of domestic output and employment. Another stream of research assesses the impact of trade-induced uncertainty on the business cycle. Among others, Caldara et al. (2019) derive a text-based measure of trade policy uncertainty.

One of the main drawbacks of these contributions, however, is that sizable movements in real variables can be induced only by very severe shocks. For instance, the framework proposed by Berthou et al. (2018) is able to generate an economic contraction by $2 \%$ of GDP by assuming 
that all countries worldwide rise bilateral tariffs on all goods by $10 \%$ at once. In Barattieri et al. (2018), a one standard deviation increase in trade barriers can shrink GDP by $0.2 \%$. An explanation to these results is provided by Furceri et al. (2018), who find that the effects of changes in protectionism are highly non-linear, with the imposition of trade barriers being much more impactful than trade liberalization. Therefore, trade models estimated with historical data might produce downward biased results, since episodes of trade liberalization strongly dominate the sample. Alternatively, as highlighted by Eichengreen (2017), the exchange rate adjustment to tariffs might have changed in the last decade.

\section{Measures of uncertainty}

Fernández-Villaverde et al. (2011) show in a closed economy model that increasing volatility of macro variables have significant real effects. One of the reasons why volatility can increase is indeed higher uncertainty related to trade policy developments.

In this regard, since the seminal paper by Bloom (2009), many researchers have tried to quantify uncertainty. A stream of this research makes use of high-frequency stock data to construct uncertainty measures. Caggiano et al. (2014), for instance, use the VIX to estimate the effect of uncertainty on US employment ${ }^{4}$, while Baker and Bloom (2013) uses the stock market reaction to natural disasters as a natural experiment to measure uncertainty shocks. The drawback of this approach is that asset valuation in the short run is mostly driven by factors other than uncertainty, in spite of the quick reaction on the part of financial markets to new information. Hence the constructed measure might relate to economic activity only indirectly.

An alternative method consists of defining uncertainty as the unexplained component of economic forecasts. Jurado et al. (2015) measure uncertainty as the error term of a forecast model based on a large time-varying VAR and show that the constructed measure of uncertainty spikes around well-known uncertainty episodes. In their approach, however, also common large shocks might be identified as uncertainty, since they inflate the residual of the forecast model by construction.

Finally, the strand of literature which is closest to our work includes several papers that extract measures of uncertainty from text data. Baker et al. (2016) and Caldara and Iacoviello (2018) define uncertainty as the share of newspaper articles discussing US or global geopolitical tensions. Caldara et al. (2019), on the other hand, count the number of occurrences of tariffsrelated words in CEO earning calls to construct an index of trade uncertainty. Differently from

\footnotetext{
${ }^{4}$ Bekaert et al. (2013) further decompose the VIX into a "risk aversion" and an "uncertainty" component.
} 
these contributions, however, our purpose is not to construct a measure of trade uncertainty, but rather to measure the intensity of trade shocks. In addition, we go beyond simple word counting in that we deploy a sophisticated learning model to derive a trade tension index.

\section{Textual analysis and machine learning in economics}

There is a growing literature that applies machine learning and textual analysis tools to economic problems ${ }^{5}$. Tillmann (2020), Gholampour and van Wincoop (2019), Bianchi et al. (2019), Hansen et al. (2018) and Ke et al. (2019) are the most recent contributions that are relevant for our paper. Specifically, Gholampour and van Wincoop (2019) extract information from the tweets of professional traders which is found to improve the forecast of exchange rate movements at high frequency. Bianchi et al. (2019), on the other hand, use Twitter ${ }^{\complement}$ announcements as proxy for shocks to the FED independence by assessing their impact on fed fund futures. A similar approach is adopted by Tillmann (2020) who shows how statements from President Trump on the FED's decisions had a downward impact on long-term interest rates. Hansen et al. (2018) as well analyse monetary policy decision-making by analysing the FOMC minutes via computation linguistic algorithms. Finally, Ke et al. (2019) construct a time series of relevant information by applying textual analysis methods to the Dow Jones Newswires. Such series is found to significantly improve the forecast of stock prices ${ }^{6}$.

These analyses mainly leverage on the existing time lag between the availability of new information in text data, their pricing-in on the part of markets and their final effect on slowermoving macroeconomic variables. Textual analysis methods can summarize these information in a quantitative indicator, in a manner which is not different from the synthesis across different time series performed by a principal component analysis. In particular, the index is assumed to include information that have not been already priced in by market participants, thus providing additional insights as to future movements of stock indices. In this paper we exploit similar techniques to quantify the "degree of protectionism" of different announcements that have not been anticipated by markets. The resulting index can be used as a proxy for the severity of the surprise of each event.

The remainder of the paper is structured as follows: Section 2 presents the main data, explains how the index is constructed and, in Section 2.5, performs the validation of the exogeneity assumption; Section 3 assesses the reaction of financial markets to rising trade tensions; Section 4 concludes.

\footnotetext{
${ }^{5}$ See Currie et al. (2019) and Gentzkow et al. (2019) for an extensive review.

${ }^{6}$ Other contributions include Werner and Murray (2004), Bollen et al. (2011), Da et al. (2011), Leung and Ton (2015), Loughran and McDonald (2011).
} 


\section{$2 \quad$ Data and the 3T-Index}

This section describes how we construct the 3T-Index, starting with the analysis of the tweets by President Trump. Important events in the Sino-American trade dispute have been often pre-announced by the US president on social medial. The most striking example are the Steel and Aluminium tariffs, which have been discussed on Twitter ${ }^{\circledR}$ posts since March 1 2018, well in advance of the official decision by the US administration on March 92018 (Figure 2). This pattern is consistent across all major actions undertaken by the US administration during the trade dispute which have strongly impacted global markets ${ }^{7}$. On top of that, not only have large policy changes been communicated by social media, but also information on the US trade stance have been leaked almost daily, thus signalling small and large developments in the SinoAmerican negotiations. Our objective is to construct a quantitative indicator of the relevance of each of those communications by selecting the ones related to trade tensions, in order to assess their medium-term effect on financial variables.

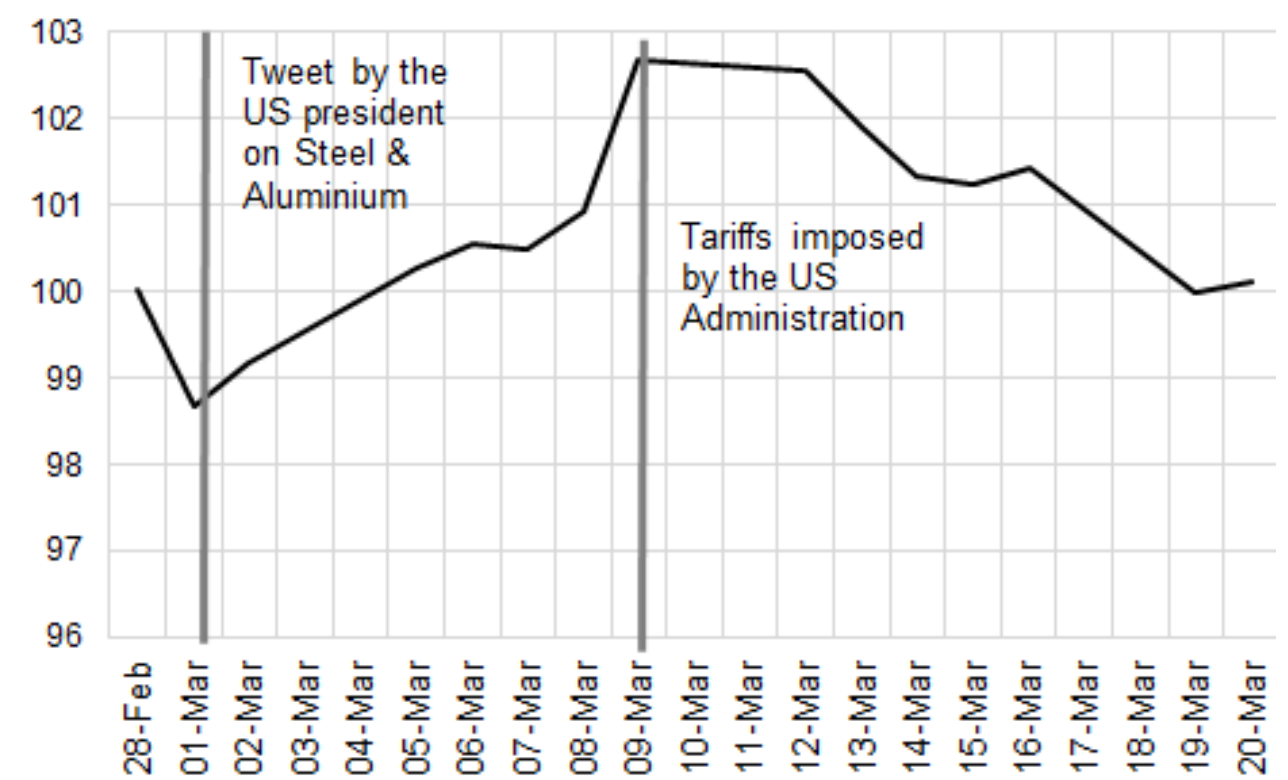

Figure 2: Reaction of the S\&P500 Index to the Steel and Aluminium tariff announcement.

Notes: the S\&P500 Index is standardized to 100 on February 282018.

Specifically, we exploit Twitter ${ }^{\complement}$ posts to assess the stance of the US communication. The baseline assumption of this paper is that such tweets, though unexpected by markets, have been nonetheless used after their release to extrapolate information on the likely stance of the US administration on a trade deal with China. We then use these tweets to track developments in the trade dispute.

A potential caveat to our analysis stems from the possible endogenous nature of the index,

\footnotetext{
${ }^{7}$ It is widely accepted by economic commentators that Trump's tweets have moved markets ("Trump's Tweets Drive The Market", Forbes, Jan 8, 2020). In this regard, additional evidence is provided in Section 2.1.
} 
especially vis-à-vis financial markets developments. For example, the language used by President Trump might have changed in response to movements in the US stock market or in the US dollar exchange rate. This would ultimately make the whole analysis biased. Therefore, in Section 2.5 we first test for the presence of endogeneity by regressing the 3T-Index on lagged and contemporaneous financial market developments. Results show that our constructed indicator cannot be systematically predicted by either US or Chinese financial data. In Section 2.4 we also report the summary statistics for the other main variables of interest.

\subsection{Preliminary evidence}

In this section we show that announcements on social media had indeed effects on financial markets. We first select days where the US President published tweets on (1) China, (2) China $\&$ Trade and (3) China \& Tariffs. Figure 3 depicts the the average absolute daily change on those days against all trading days for the following variables: the S\&P 500 Index, the Shanghai Stock Market Index, the JP Morgan EMEs stock market index and the nominal effective exchange rate of the US dollar, the renminbi and emerging market economies ${ }^{8}$. All in all, the average absolute change of the variables of interest is higher on days featuring releases of tweets related to China and tariffs (green bars), compared to other days (blue bars), the only exception to this trend being the change in the US dollar exchange rate. This stylized fact already suggests that markets were responsive to social media communications related to the developments of trade negotiations between the US and China.

We check more formally for the significance of such changes by setting up an event study as follows:

$$
\Delta y_{t-1, t+k}=\alpha_{k}+\beta_{k} \text { Event }_{t}+\varepsilon_{t+k}
$$

where $\Delta y_{t-1, t+k}$ is the log change in the variable of interest between $t-1$ and $t+k$ for $k=0,1,2 .^{9}$ Event $t_{t}$ is a dummy taking value of $1(-1)$ for days with positive (negative) tweets as identified by the Bloomberg "trade war" timeline. ${ }^{10}$ The coefficient $\beta_{k}$, therefore, captures the impact of such events relative to the average change of the dependent variable at horizon $k$. If $\beta_{k}$ is positive (negative) a positive event leads to a larger positive (negative) change of the dependent variable relative to all other days.

We consider four key financial variables: the S\&P500, the Shangahai stock market index, the US dollar NEER and the bilateral Chinese renminbi/US dollar exchange rate. Results

\footnotetext{
${ }^{8}$ We use absolute changes to avoid that positive and negative changes net out in the averaging.

${ }^{9}$ Notice that for $k=0$ the dependent variable is the daily change.

${ }^{10}$ See: https://www.bloomberg.com/news/articles/2019-08-28/u-s-china-trade-war-timeline-what-s-happenedsince-may-2019. Table B.1 reports the events and the related tweets used to construct the dummies.
} 


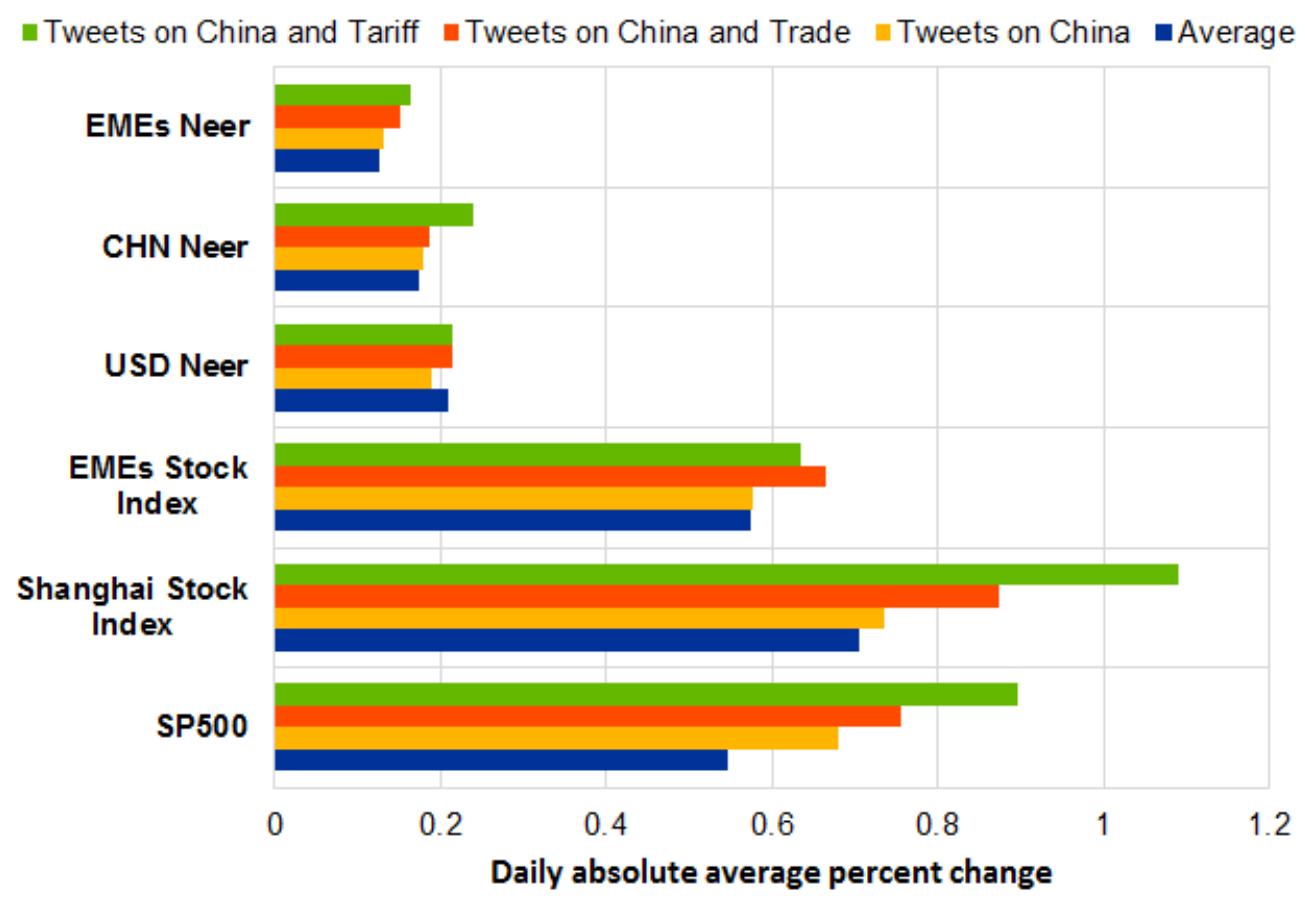

Figure 3: Average absolute daily changes in days with tweets related to (1) China and tariffs; (2) China and trade; (3) China; (4) all other days.

from the estimation of Equation (2.1) are reported in Table 1. Large events in the trade war, as captured by the timeline, had indeed a significant effect on financial markets. Notably, positive developments in the trade war (release in trade tensions) lead to an increase in the stock valuations in the US and China and a depreciation of the US dollar, both in nominal effective terms and bilaterally against China. On the contrary, rising trade tensions negatively impact stock markets and trigger an appreciation of the US dollar.

The event study outcome seems to validate the preliminary evidence depicted in Figure 3: large events in the trade dispute between the US and China had an impact on financial markets. However, the framework provided by Equation (2.1) has several limitations which make it less appealing for an analysis over the medium-term.

First, the events considered are only the largest and most significant in the trade dispute history, which means that conclusions from the event study cannot be generalized to any event not explicitly included in the sample. Second, the sampled events are considered as all equally important, while we know that some of them have been more relevant than others. Third, announcements on the trade dispute have often been contradictory, with positive statements being closely followed (even within the same day) by negative ones. This complicates the evaluation of single events as it is hard, with simple dummies, to disentangle which of them have been dominated. Consider for example the sequence of tweets started on May 13 2018. At 15:03 a tweet was posted, suggesting that the US administration would commit to reduce barriers on 
Table 1: Daily impact of trade war events

\begin{tabular}{lccc|cccc}
\hline \hline \multicolumn{4}{c}{ S\&P 500 index } & \multicolumn{4}{c}{ Shanghai stock narket index } \\
\hline \hline$k$ & 0 & 1 & 2 & & 0 & 1 & 2 \\
\hline \hline$\beta_{k}$ & $0.104^{*}$ & $0.181^{* *}$ & $0.228^{* *}$ & $\beta_{k}$ & $0.106^{*}$ & $0.335^{* * *}$ & $0.326^{* * *}$ \\
& $(0.062)$ & $(0.084)$ & $(0.111)$ & & $(0.059)$ & $(0.078)$ & $(0.118)$ \\
$\alpha_{k}$ & 0.070 & $0.169^{*}$ & $0.234^{* *}$ & $\alpha_{k}$ & 0.037 & -0.040 & -0.040 \\
& $(0.064)$ & $(0.098)$ & $(0.104)$ & & $(0.065)$ & $(0.103)$ & $(0.118)$ \\
Obs. & 212 & 161 & 155 & Obs. & 212 & 161 & 155 \\
$R^{2}$ & 0.011 & 0.020 & 0.024 & $R^{2}$ & 0.012 & 0.057 & 0.035 \\
\hline \hline \multicolumn{4}{c}{ USD NEER } & & \multicolumn{5}{c}{ CHN/USD } \\
\hline \hline$\beta_{k}$ & -0.027 & $-0.083^{* * *}$ & $-0.086^{* *}$ & $\beta_{k}$ & -0.040 & $-0.134^{* * *}$ & $-0.151^{* * *}$ \\
& $(0.019)$ & $(0.020)$ & $(0.038)$ & & $(0.026)$ & $(0.028)$ & $(0.046)$ \\
$\alpha_{k}$ & -0.005 & -0.008 & 0.006 & $\alpha_{k}$ & -0.006 & -0.025 & 0.008 \\
& $(0.020)$ & $(0.030)$ & $(0.035)$ & & $(0.016)$ & $(0.025)$ & $(0.031)$ \\
Obs. & 212 & 161 & 155 & Obs & 212 & 161 & 155 \\
$R^{2}$ & 0.008 & 0.047 & 0.031 & $R^{2}$ & 0.022 & 0.140 & 0.109 \\
\hline \hline
\end{tabular}

Notes: estimates of Equation (2.1) on daily data for the S\&P500 index, the Shanghai stock market index, the USD nominal effective exchange rate and the CHN/USD exchange rate. The dependent variable is expressed in log changes $\times 100$ and Event $t_{t}$ is a dummy of value $1(-1)$ for positive (negative) tweets as identified by the Bloomberg "trade war" timeline. We consider the contemporaneous daily change $(k=0)$ and the change 1 and 2 days after the event. Robust standard errors are reported in parentheses with ${ }^{* * *} p<0.01,{ }^{* *} p<0.05,{ }^{*} p<0.1$ confidence intervals.

the imports of ZTE, a Chinese tech giant. This is clearly a positive and relevant development. However, already at 19:22 another tweet was published on the the US President account stating: "negotiations have been so one sided in favor of China for so many years that it is hard for them to make a deal that benefits both countries", a clear setback in negotiations. A careful evaluation of the trade stance needs then to take into account these intra-day communication changes. Fourth, events in the trade war have escalated over time, involving more than a single tweet. A throughout indicator of the trade stance would therefore need to combine the information from several tweets and to weight them by relevance.

The index we derive in the next sections addresses each of these issues, in that it quantifies the relative strength (positive or negative) of each tweet, thus allowing to weight and compare different events. In addition, it also automatically disentangles trade-related tweets from all others. Finally, by constructing a complete time-series for the development of the trade dispute, we are able to evaluate the impact on stock markets of each event assessing the medium-term implications of escalating trade tensions.

\section{$2.2 \quad$ A textual analysis approach to protectionism}

To go beyond a simple event study approach and evaluate the impact of rising trade tensions over longer horizons, we develop a quantitative indicator for the degree of protectionism of each 
communication by the US President. The index allows us to evaluate each tweet, distinguishing which part of it (if any) is linked to trade tensions and which is not. We aggregate the index at a weekly frequency taking into account all communications related to trade tensions and not limiting only to the largest and most significant events. The weekly aggregation is preferable for our analysis as several events occur outside trading hours or during weekends. It is worth underlining that only tweets discussing trade tensions are used to compute the indicator and that the proposed methodology automatically selects them based on historical regularities.

There are few important caveats that need to be considered in this analysis. First, tweets concerning trade tensions need to be systematically teased out from all other tweets. This is even more complicated, given that a single tweet can touch upon different topics at once. Second, not all communications are the same. Although the most relevant of them are included in the Bloomberg's Trade War history, there are however many more that are not included in the list, but contributed to increase tensions on a daily basis. These tweets contain important information for our analysis, as they capture the vast majority of developments in trade tensions, which are not as extreme as the events in the Timeline. Finally, all communications need to be systematically evaluated and converted into a quantitative indicator for aggregation.

The literature on computational linguistic has developed several alternative methods to conduct this type of analyses ${ }^{11}$. Historically the first approach, and by far the most straightforward to implement, is the so-called word count: in each text sample the words associated to a specific sentiment are counted and the indicator is the ratio between them and all words in text ${ }^{12}$. This methodology is simple, but suffers from an important drawback: the researcher needs to set a priori a dictionary of sentiment words which outlines the list of words associated to each sentiment. There exist some pre-compiled dictionaries, e.g., the Harvard-IV ${ }^{13}$, which provide a list of "positive" and "negative" words. These classifications are constructed based on standardized language patterns used in texts discussing general topics. For this reason, they often perform poorly when applied to specific language or specialized topics. Gholampour and van Wincoop (2019), for example, show that such dictionaries do not capture well economic assessments. Alternatively, some authors have came up with their own dictionaries, tailored to the text and context of interest. This solution, unfortunately, could not suit our sample, as all tweets come from the same source and use a very specific language. Moreover, most tweets are unrelated to trade tensions and should not be used to inform the classification of words for the subsample of posts we are focusing on.

\footnotetext{
${ }^{11}$ Refer to Gentzkow et al. (2019) for applications to economics.

${ }^{12}$ This approach is used, among others, by Bloom (2009) and Caldara et al. (2019).

${ }^{13}$ Other examples are Wilson et al. (2005), Hutto and Gilbert (2014) and Chung and Pennebaker (2004).
} 
As an alternative to these problems, we apply an algorithm that jointly identifies the words used in tweets about trade tensions and their relative "sentiment" ${ }^{14}$. This approach has several advantages. First, we do not need to make any a priori choice about the relevance of specific words, but we extract information from the available text so that the resulting indicator is really tailored to the specific analysis. Second, selected words do not have a binary connotation ("positive" vs "negative"), but receive a specific score so that words can be ranked in an ordinal manner and compared to others ${ }^{15}$. This is a key and important characteristic of the model, which allows to automatically select the text used to compile the indicator. Text samples where none of the selected words is present receive zero score and are automatically excluded from the computation of the indicator. Third, the set of words is defined by a statistical model exploiting the correlation across different words. In other terms, the choice is based on the occurrence of words. For example, those used in a text sample with a negative connotation are picked as negative and the more often they are used in such context, the higher is the score associated to them.

Practically, the algorithm works in three steps. First, a training sample (generally a subset of all available data) of relevant text needs to be identified. This is the only choice that the researcher needs to take a priori. The algorithm then uses that sample to select and score words associated to the desired topics. In this application we use the tweets included in the Bloomberg's Trade War history before 2018, as we have shown how those tweets coincided with events that had a significant impact on markets (Table 1).

The training sample provides us with the writing patterns featured by trade-related announcements, thus ensuring that our indicator captures only communications pertaining trade. Concretely, and this is the second step, a statistical model is estimated on the training sample. Each word enters the regression as a dummy variable and is used to explain the text used for the training ${ }^{16}$. Intuitively, dummies associated to non-relevant words should have a zero coefficient, while positive or negative coefficients capture the relative importance of selected words. In many applications, including ours, it is impossible to consider all the dummies at the same time as the number of words exceeds the number of text in the training sample (in our case, after standardization, the training sample includes more than 600 unique words). For this reason, the model is estimated using shrinking regression methods that score only the relevant dummies. This is a common choice in the textual analysis literature (Gentzkow et al. (2019),

\footnotetext{
${ }^{14}$ In other terms the algorithm distinguishes words that contribute to ease tensions (e.g., the expression "great trade deal") or increase them (e.g., the expression "increase tariffs").

${ }^{15}$ As an example, the algorithm puts more weight on the use of the word "barriers" rather than "deficit" despite both of them are associated with an increase of tensions.

${ }^{16}$ Each text sample is scored so that the dummies for words are used to explain the score. In our application we rely on the Bloomberg's "trade war" timeline for scoring, all scored tweets are reported in the Appendix.
} 
Hansen et al. (2018), Ke et al. (2019)).

The final step consists of constructing an indicator that is simply the "fitted value" of the model for all texts in the sample (including the "observations" not used for the training). Each text, in fact, receives a score given by the sum of the scores of all words contained therein. For example, if a tweet is completely unrelated to trade tensions, all the coefficients would be zero and, hence, the overall score would be zero. As such, the text is identified as non-related to trade announcements and becomes irrelevant for the later part of the analysis.

This approach is particularly useful to identify text samples that discuss mixed topics as the part of the text unrelated to trade tensions would get zero score, while the part discussing them would contribute positively or negatively. The next section presents more in detail the methodology used, which is an example of a so-called "supervised machine learning" algorithm, in that the model needs to be provided with a set of relevant observations for the training sample. Once this is done, however, the selection and scoring of words based on the sample is completely automatized.

\subsection{Construction of the 3T-Index}

In this section, we formally explain the algorithm used to quantify the change in the protectionist stance of each tweet by President Trump related to the US-China trade negotiations. We name the resulting indicator the Trade Tensions Tweet Index (3T-Index), which is scaled so that higher values are associated to a more accommodating trade stance towards China, whereas harsher threats of trade barriers and retaliation correspond to lower values of the index.

The first step consists of collecting all tweets by President Trump from January 2016 to November $2019^{17}$. These tweets cover the period since the beginning of President's Trump

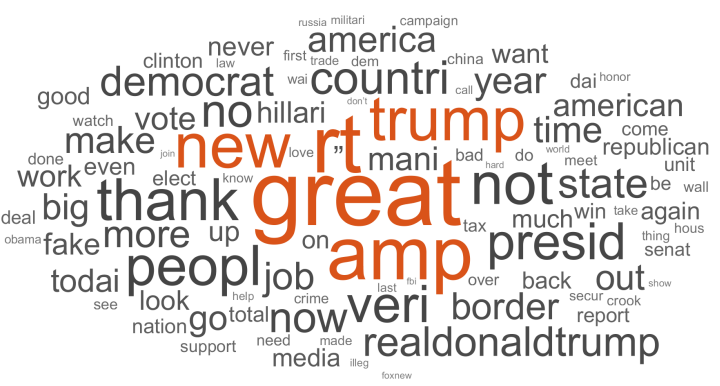

(a) All tweets since January 2016

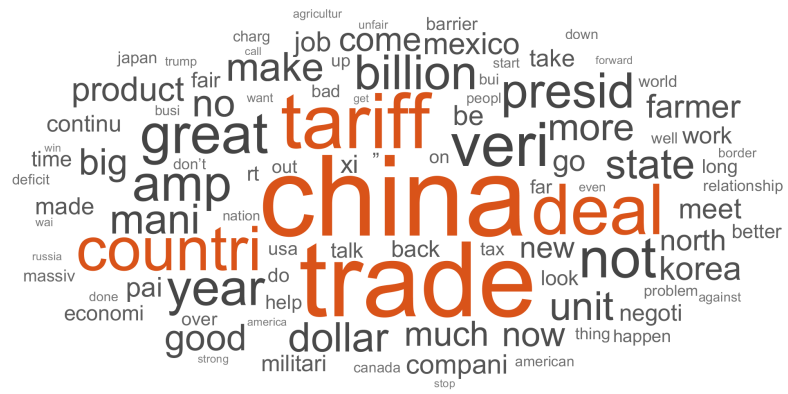

(b) Tweets in Bloomberg's Trade War timeline

Figure 4: Word clouds

\footnotetext{
${ }^{17}$ These tweets can be downloaded directly from Twitter or from the Trump Twitter Archive. The tweets are cleaned using standard methods. For instance, we remove all stop-words, singular and plural endings and include certain bigrams (i.e., two subsequent words are treated as one unit; for example, "good deal" is treated differently from "bad deal"), as commonly done in textual analysis applications (Gholampour and van Wincoop (2019), Werner and Murray (2004)). Appendix A reports the full list of standardization techniques.
} 
presidential campaign, when he started tweeting about (what was wrong with) the trade deal with China.

Figure 4 compares word clouds for all tweets since 2016 (Figure 4a) and only for those related to the Bloomberg's Trade War timeline (Figure 4b). In each cloud, words are thicker depending on the frequency of appearance. Hence, they provide an indication of the topics covered in the underlying text. At a first glance, it seems that tweets in the "trade war" sample use a different language compared to the others. Figure 4b indeed shows that "China", "tariff", "trade" and "deal" are the most used words compared to "great", "Trump" and "new", which on the other hand prevail in Figure 4a. Comparing the two word clouds also suggests that tweets in the training sample discuss very specific topics like trade deals and the US dollar and are closely related to developments in trade, which make them very well-suited to train the model.

In this regard, the algorithm actually goes beyond the simple word counting, as it quantifies to what extent each tweet is tilted towards "protectionism". Notably, tweets of the Bloomberg's Trade War timeline are analysed using a supervised machine learning algorithm, since standard dictionaries (even economic ones) are not suitable to construct a sentiment indicator based on tweets' text. Constructing an ad-hoc dictionary, as done by Gholampour and van Wincoop (2019) on the basis of the language used by traders in trading rooms, is not an alternative either for three main reasons: i) the tweets we focus on do not use a standard language set; ii) second, they are all taken from the same source, which does not allow to identify common patterns; iii) third, some tweets use idiomatic words or sentences that are missing in pre-compiled dictionaries. Given this, the most viable approach consists of adopting an algorithm to identify the sets of words that are more frequently deployed in episodes of heightened trade tensions with China and, then, construct the sentiment indicator.

With this aim, we first retrieve the single tweets corresponding to the events listed in the Bloomberg's Trade War timeline before January $2019^{18}$ and score them between 1 and -1 depending on whether the tweet is associated to a relaxation of trade tensions or, on the contrary, to a tightening. These tweets and their relative scores, provides us with the training sample for the algorithm ${ }^{19}$.

We then model tweets' sentiment by fitting an elastic net framework on the training sample. This statistical method allows to select relevant regressors among a large pool of variables which cannot be used simultaneously in the estimation. The elastic net combines also the benefits of the lasso and the ridge regressions, in that the framework: i) includes a penalty term in the

\footnotetext{
${ }^{18}$ See https://www.bloomberg.com/news/articles/2019-08-28/u-s-china-trade-war-timeline-what-s-happenedsince-may-2019.

${ }^{19}$ The complete list of tweets and related scores that make the training sample up are reported by Table B.2 in Appendix B.1
} 
score function that constrains the number of estimated coefficients (in this way models with redundant explanatory variables are penalized); ii) shrinks the number of coefficients to zero the higher the penalty term becomes ${ }^{20}$. Therefore, the elastic net selects by construction more parsimonious models, a feature which is particularly useful when dealing with a large set of potential explanatory variables that are also highly correlated ${ }^{21}$. Specifically, the model solves:

$$
\min _{\beta_{0}, \beta}\left[\frac{1}{2 N} \sum_{i=1}^{N}\left(S_{i}-\beta_{0}-x_{i}^{T} \beta\right)^{2}+\lambda P_{\alpha}(\beta)\right],
$$

with

$$
P_{\alpha}(\beta)=\frac{(1-\alpha)}{2}\|\beta\|^{2}+\alpha\|\beta\|
$$

In Equation (2.2), $S_{i}$ is the score attached to tweet $i, x_{i}$ is a matrix of dummy variables equal to 1 if a word is present in tweet $i$ and zero otherwise, $\beta_{0}$ and $\beta$ are the estimated parameters, $\lambda$ and $\alpha \in[0,1]$ are tuning parameters. In particular, $\beta_{0}$ is the loading of the constant, $\beta$ is a vector of loadings for each dummy variable in $x_{i}$ and $\lambda$ is the penalization parameter. Hence, the higher is $\lambda$, the fewer words (dummies) are included as explanatory variables. Finally, $\alpha$ is a scaling parameter that sets the penalty function in Equation (2.3) as a weighted average of the penalty under the lasso $(\alpha=1)$ and the ridge $(\alpha=0)$. When $\lambda$ is zero, Equation $(2.2)$ simply coincides with the OLS estimator.

The elastic net approach presents a distinct advantage, in that it allows to select the most powerful predictors in $x_{t}$ while maintaining (feasible) degrees of freedom even with very large sets of potential explanatory variables. In our specific case, the model selects only 27 out of more than 600 unique words in the training sample to construct the final sentiment indicator. Figure 5 reports the trace plot for the estimated coefficients and the optimal value of $\lambda$, i.e. the joint path of the estimated coefficients and $\lambda$ from the initial condition to the optimum $\left(\lambda^{*}\right)^{22}$. The latter is detected by using a five fold cross-validation approach, whereby $\lambda$ is chosen based on the mean squared prediction error. In practice, the algorithm draws a value of $\lambda$ and $\alpha$, estimates Equation (2.2) for different combinations of explanatory variables (dummies in $x_{i}^{T}$ ) and selects the model with the lowest score. It then moves on to another draw of $\lambda$ and $\alpha$ until convergence (i.e. the score of Equation (2.2) stops improving). Figure 5 plots the loadings $\beta$ associated to the 27 selected dummies at each iteration from the starting point of the optimization $(\lambda=0.25)$ to the optimum $(\lambda=0.04)$. The final values of $\beta$ for $\lambda=0.04$ are the loadings selected by the model.

\footnotetext{
${ }^{20}$ Refer to Tibshirani (1996), Zou and Hastie (2005) and Hastie et al. (2009) for further details.

${ }^{21}$ In this exercise each word is treated as a separate independent variable.

${ }^{22}$ In Table B.3 of the Online Appendix we report the full list of the selected words with the related loadings.
} 


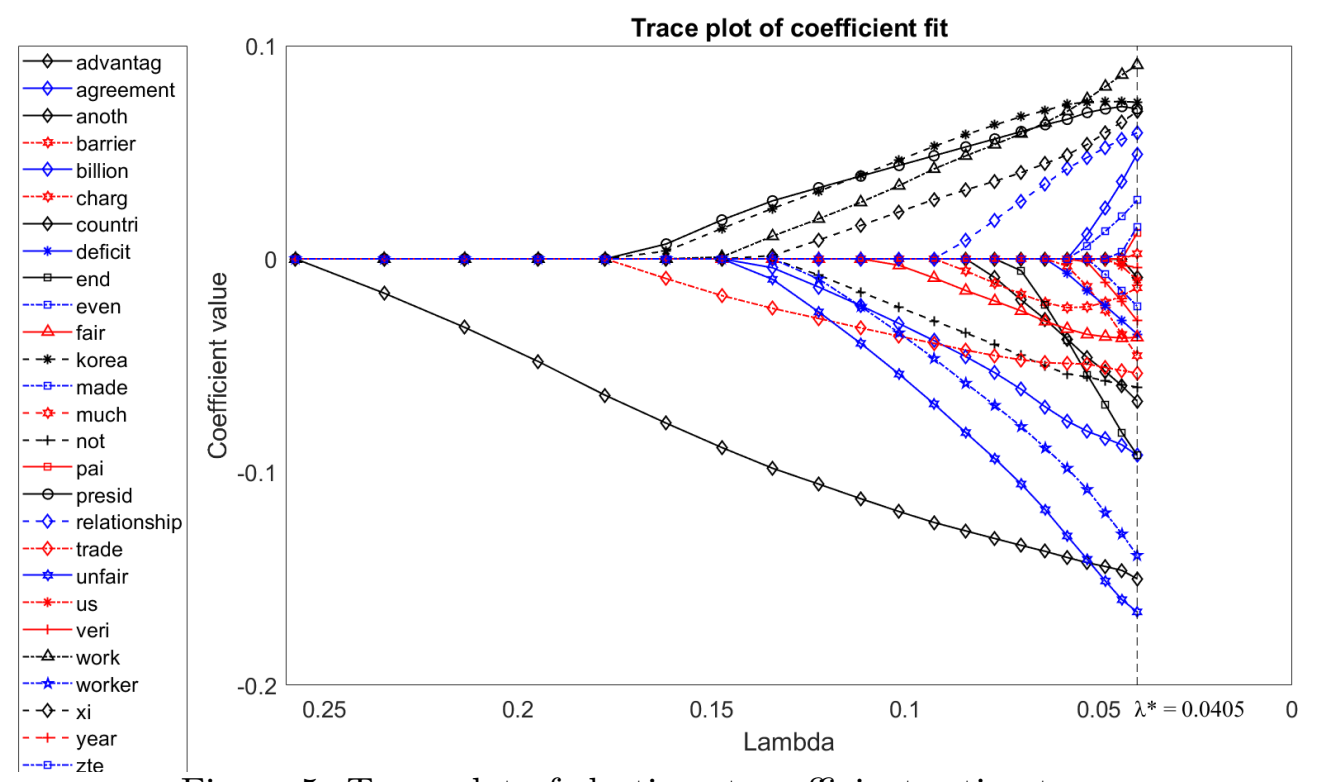

Figure 5: Trace plot of elastic net coefficient estimates

We use the estimated coefficients to fit the model on the remaining tweets after 2018. The model's predicted values are the implied sentiment from each tweet, the 3T-Index. Figure 6 shows the 3T-Index at weekly frequency against the most relevant Bloomberg's Trade War timeline events ${ }^{23}$. The index tracks relatively well negative events in the sample, which are also largely dominant. The only relevant positive event, the tweet on May 132018 in which President Trump committed to remove barriers to the imports of the Chinese tech firm ZTE, is missed. As also explained in Section 2.1 above, this is mainly due to the peculiar communication strategy adopted by the US President on that occasion: at 15:03 President Trump tweeted in support of ZTE but, in a later tweet on the same day (19:22), he largely scaled that commitment down ${ }^{24}$. The index averages out the events, thus damping the overall daily effect. Communication in the previous week, on the contrary, was mainly positive and this is the reason why the index spikes before this event.

\subsection{Other data}

Other relevant weekly data are taken from Haver Analytics and cover the period between January 2016 and November 2019. Table 2 reports the list of the variables included in our dataset, together with their summary statistics. The 3T-Index is aggregated at weekly frequency to smooth out volatility in the daily sentiment indicator and account for weeks where several trade-related tweets were posted.

\footnotetext{
${ }^{23}$ When there are more than one tweet in each day or week we sum the index in that day or week. Refer to Figure B.1 in the Appendix for the daily version of the index.

${ }^{24}$ Refer to Table B.2 in the Appendix.
} 


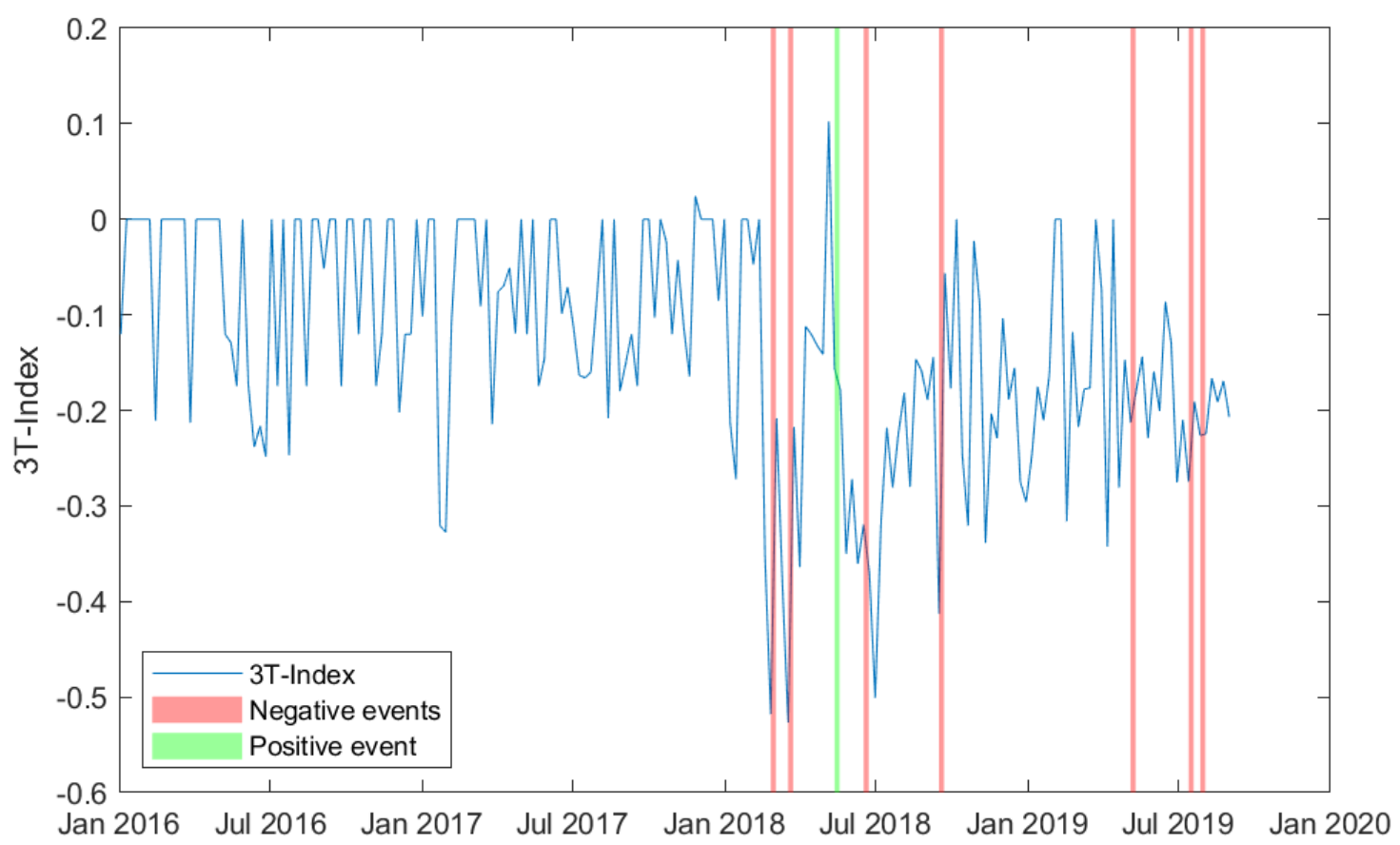

Figure 6: Weekly 3T-Index (blue solid line) and Bloomberg's trade war events (vertical bars)

Table 2: Summary statistics

\begin{tabular}{|c|c|c|c|c|c|c|c|c|}
\hline & SP500 & Dow Jones & Shanghai Stock & EME Stock & $\begin{array}{l}\text { USD NEER } \\
\end{array}$ & CHN NEER & EME NEER & USD/EUR \\
\hline Mean & 2534.46 & 22634.12 & 3031.20 & 703.73 & 119.95 & 117.22 & 95.18 & 1.13 \\
\hline Std dev. & 323.56 & 3384.30 & 231.09 & 76.63 & 3.03 & 2.46 & 1.37 & 0.04 \\
\hline Min & 1850.27 & 15918.04 & 2481.51 & 508.50 & 113.09 & 112.84 & 91.90 & 1.04 \\
\hline $\operatorname{Max}$ & 3142.19 & 28100.89 & 3552.40 & 878.92 & 125.84 & 124.21 & 97.97 & 1.24 \\
\hline Start & 01/01/2016 & $01 / 01 / 2016$ & $01 / 01 / 2016$ & $01 / 01 / 2016$ & $01 / 01 / 2016$ & $01 / 01 / 2016$ & $01 / 01 / 2016$ & $01 / 01 / 2016$ \\
\hline \multirow[t]{2}{*}{ End } & $29 / 11 / 2019$ & $29 / 11 / 2019$ & $29 / 11 / 2019$ & $29 / 11 / 2019$ & $29 / 11 / 2019$ & $29 / 11 / 2019$ & $29 / 11 / 2019$ & $29 / 11 / 2019$ \\
\hline & VIX & $\overline{\text { US 2-year yield }}$ & US 10-year yield & Citi US Surprise & EMBI+ & Shanghai bond price & & \\
\hline Mean & 14.80 & 1.68 & 2.32 & -1.52 & 807.03 & 164.38 & & \\
\hline Std dev. & 4.05 & 0.69 & 0.47 & 33.94 & 39.52 & 6.36 & & \\
\hline Min & 9.34 & 0.58 & 1.38 & -76.38 & 698.33 & 154.58 & & \\
\hline Max & 31.51 & 2.94 & 3.21 & 78.94 & 887.26 & 177.45 & & \\
\hline Start & $01 / 01 / 2016$ & $01 / 01 / 2016$ & $01 / 01 / 2016$ & $01 / 01 / 2016$ & $01 / 01 / 2016$ & $01 / 01 / 2016$ & & \\
\hline End & $29 / 11 / 2019$ & $29 / 11 / 2019$ & $29 / 11 / 2019$ & $29 / 11 / 2019$ & $29 / 11 / 2019$ & 29/11/2019 & & \\
\hline
\end{tabular}

\subsection{Endogeneity checks}

A major caveat to our approach might derive from the potential endogeneity of the US President's communication strategy in the context of the "trade war" vis-à-vis the developments on financial markets. For example, the President's stance towards China might have become harsher if the US stock market underperformed or the US dollar appreciated. If this was the case, the tweets would be endogenous to financial variables and the 3T-Index could not be used as instrument of the harshness of the US administration's trade stance.

It is possible to test for the presence of endogeneity by regressing the 3T-Index on contem- 
poraneous and lagged stock indices and the (log-change of) US dollar NEER ${ }^{25}$ :

$$
\Delta \text { Index }_{t}=\alpha+\sum_{i=0}^{L} \beta^{i} \Delta S P 500_{t-i}+\sum_{i=0}^{L} \gamma^{i} \Delta N E E R_{t-i}^{U S D}+\sum_{i=0}^{L} \delta^{i} \Delta S t o c k_{t-i}^{C H N}+\varepsilon_{t}
$$

If the relevant coefficients in Equation (2.4) were found to be statistically significant, this would mean that financial variables can somewhat drive the 3-T Index, thus hindering its validity as exogenous instrument to capture trade tension shocks. The set of regressors in Equation (2.4) also includes the contemporaneous changes in financial market variables to test for the existence of common shocks that might move both financial markets and the 3-T Index. Results reported in Table 3 show that changes in the 3T-Index are not systematically predicted by developments in financial markets as measured by changes in the US stock market, the Chinese stock market and the US dollar NEER, the latter being also a measure of global risk. All specifications reported show non-significant coefficients and explain a very limited share of the volatility of the index. Moreover, results of the $F-$ test show that coefficients are not jointly significant. The Index is found to be exogenous to both domestic and foreign financial market developments also when estimating Equation (2.4) at the daily frequency (Table 4) ${ }^{26}$.

In the following sections we use the index at weekly frequency, which is better suited to analyse the medium-term impact of trade tensions on financial markets for several reasons: i) many relevant events have occurred outside trading hours. Daily financial variables would therefore miss the contemporaneous effects and would be biased by the information priced-in by markets before the next opening (this can indeed be significant in the case of weekends); ii) it has often been the case that negative (positive) communications have closely followed positive (negative) ones within the same day or week. In this context, financial markets receive opposite signals that could off-set each other, thus adding noise to the estimation; iii) not all communications have the same relevance and some of them might be more relevant than others.

Aggregating at weekly frequency then allows to smooth part of that volatility by netting positive and negative communication within the same week and computing the prevailing stance in that time frame. The aggregation is made possible by the specific characteristics of our index, that allow to directly compare and cumulate different events using their implied score.

\footnotetext{
${ }^{25}$ As a robustness check, Table B.4 in the Appendix shows that results are robust to using the 3-T Index in levels instead of first-difference.

${ }^{26}$ Table B.5 reports the same regression with the index in levels.
} 
Table 3: Estimates from equation Equation (2.4) at weekly frequency

\begin{tabular}{|c|c|c|c|c|c|c|c|}
\hline & $\begin{array}{l}\text { Model } \\
(1)\end{array}$ & $\begin{array}{c}\text { Model } \\
(2)\end{array}$ & $\begin{array}{c}\text { Model } \\
(3)\end{array}$ & $\begin{array}{l}\text { Model } \\
(4)\end{array}$ & $\begin{array}{c}\text { Model } \\
(5)\end{array}$ & $\begin{array}{c}\text { Model } \\
(6)\end{array}$ & $\begin{array}{c}\text { Model } \\
(7)\end{array}$ \\
\hline$\overline{\Delta S P 500_{t}}$ & $\begin{array}{l}-0.096 \\
(0.588)\end{array}$ & & & $\begin{array}{l}-0.090 \\
(0.620)\end{array}$ & $\begin{array}{l}-0.203 \\
(0.583)\end{array}$ & & $\begin{array}{l}-0.165 \\
(0.609)\end{array}$ \\
\hline$\Delta S P 500_{t-1}$ & $\begin{array}{c}0.147 \\
(0.984)\end{array}$ & & & $\begin{array}{c}0.296 \\
(0.999)\end{array}$ & $\begin{array}{c}0.128 \\
(1.027)\end{array}$ & & $\begin{array}{c}0.231 \\
(1.031)\end{array}$ \\
\hline$\Delta S P 500_{t-2}$ & $\begin{array}{c}0.706 \\
(0.839)\end{array}$ & & & $\begin{array}{c}0.414 \\
(0.849)\end{array}$ & $\begin{array}{c}0.691 \\
(0.819)\end{array}$ & & $\begin{array}{c}0.478 \\
(0.832)\end{array}$ \\
\hline$\Delta N E E R_{t}^{U S D}$ & & $\begin{array}{c}0.129 \\
(1.574)\end{array}$ & & $\begin{array}{c}0.035 \\
(1.653)\end{array}$ & & $\begin{array}{c}0.493 \\
(1.629)\end{array}$ & $\begin{array}{c}0.373 \\
(1.680)\end{array}$ \\
\hline$\Delta N E E R_{t-1}^{U S D}$ & & $\begin{array}{c}1.581 \\
(1.900)\end{array}$ & & $\begin{array}{c}1.709 \\
(2.030)\end{array}$ & & $\begin{array}{c}1.334 \\
(2.056)\end{array}$ & $\begin{array}{c}1.318 \\
(2.138)\end{array}$ \\
\hline$\Delta N E E R_{t-2}^{U S D}$ & & $\begin{array}{c}-3.018^{*} \\
(1.591)\end{array}$ & & $\begin{array}{l}-2.694 \\
(1.658)\end{array}$ & & $\begin{array}{l}-2.587 \\
(1.711)\end{array}$ & $\begin{array}{l}-2.368 \\
(1.756)\end{array}$ \\
\hline$\Delta S t o c k_{t}^{C H N}$ & & & $\begin{array}{c}0.382 \\
(0.483)\end{array}$ & & $\begin{array}{c}0.474 \\
(0.493)\end{array}$ & $\begin{array}{c}0.445 \\
(0.505)\end{array}$ & $\begin{array}{c}0.482 \\
(0.514)\end{array}$ \\
\hline$\Delta S_{t o c k} k_{t-1}^{C H N}$ & & & $\begin{array}{l}-0.555 \\
(0.477)\end{array}$ & & $\begin{array}{c}-0.707 \\
(0.514)\end{array}$ & $\begin{array}{l}-0.544 \\
(0.495)\end{array}$ & $\begin{array}{c}-0.672 \\
(0.532)\end{array}$ \\
\hline$\Delta S t o c k_{t-2}^{C H N}$ & & & $\begin{array}{c}0.816 \\
(0.549)\end{array}$ & & $\begin{array}{c}0.645 \\
(0.521)\end{array}$ & $\begin{array}{c}0.679 \\
(0.580)\end{array}$ & $\begin{array}{c}0.562 \\
(0.548)\end{array}$ \\
\hline Constant & $\begin{array}{c}-0.002 \\
(0.006)\end{array}$ & $\begin{array}{c}-0.001 \\
(0.006)\end{array}$ & $\begin{array}{c}-0.001 \\
(0.006)\end{array}$ & $\begin{array}{c}-0.002 \\
(0.006)\end{array}$ & $\begin{array}{c}-0.002 \\
(0.006)\end{array}$ & $\begin{array}{l}-0.000 \\
(0.006)\end{array}$ & $\begin{array}{c}-0.002 \\
(0.006)\end{array}$ \\
\hline Observations & 190 & 190 & 190 & 190 & 190 & 190 & 190 \\
\hline F test & 0.757 & 1.208 & 1.017 & 0.879 & 0.684 & 1.374 & 0.999 \\
\hline F prob & 0.519 & 0.308 & 0.386 & 0.511 & 0.663 & 0.227 & 0.442 \\
\hline$R^{2}$ & 1.20 & 1.21 & 1.22 & 1.22 & 1.23 & 1.24 & 1.24 \\
\hline
\end{tabular}

Notes: explanatory variables are in log-differences; the China stock index is the Shanghai stock market index. T-stats reported in parenthesis below coefficients and computed based on HAC standard errors. ${ }^{* * *} p<0.01,{ }^{* *} p<0.05,{ }^{*} p<0.1$

\section{Impact on financial variables}

In this section, we assess the effect of an increase in the US-China trade tensions by means of local projections à là Jordà (2005). Notably, we estimate:

$$
y_{t+k}=\alpha+\beta^{k} \hat{S}_{t}+\delta y_{t-1}+\Gamma^{\prime} X_{t}+\varepsilon_{t}
$$

where $y_{t}$ is the (logged) variable of interest, $X_{t}$ collects a set of control variables and $\hat{S}_{t}$ is the 3T-Index, given by the fitted values from Equation (2.2). As $\hat{S}_{t}$ is exogenous to financial market movements ${ }^{27}$, the coefficient $\beta^{k}$ can be interpreted as the impact of changes in $\hat{S}_{t}$ on the dependent variable at any future horizon $k$ going from 0 (i.e. the impact effect) to 12 weeks

\footnotetext{
${ }^{27}$ See Section 2.5 .
} 
Table 4: Estimates from equation Equation (2.4) at daily frequency

\begin{tabular}{|c|c|c|c|c|c|c|c|}
\hline & $\begin{array}{l}\text { Model } \\
\text { (1) }\end{array}$ & $\begin{array}{l}\text { Model } \\
(2)\end{array}$ & $\begin{array}{l}\text { Model } \\
(3)\end{array}$ & $\begin{array}{l}\text { Model } \\
(4)\end{array}$ & $\begin{array}{l}\text { Model } \\
(5)\end{array}$ & $\begin{array}{c}\text { Model } \\
(6)\end{array}$ & $\begin{array}{c}\text { Model } \\
(7)\end{array}$ \\
\hline$\overline{\Delta \triangle S P 500_{t}}$ & $\begin{array}{c}1.164 \\
(4.944)\end{array}$ & & & $\begin{array}{l}-0.080 \\
(5.477)\end{array}$ & $\begin{array}{c}3.250 \\
(4.671)\end{array}$ & & $\begin{array}{c}1.856 \\
(5.096)\end{array}$ \\
\hline$\Delta S P 500_{t-1}$ & $\begin{array}{c}0.821 \\
(4.010)\end{array}$ & & & $\begin{array}{l}-0.447 \\
(3.882)\end{array}$ & $\begin{array}{c}1.432 \\
(4.482)\end{array}$ & & $\begin{array}{c}0.292 \\
(4.671)\end{array}$ \\
\hline$\Delta S P 500_{t-2}$ & $\begin{array}{c}3.729 \\
(3.535)\end{array}$ & & & $\begin{array}{c}3.420 \\
(3.718)\end{array}$ & $\begin{array}{c}2.266 \\
(3.164)\end{array}$ & & $\begin{array}{c}2.338 \\
(3.275)\end{array}$ \\
\hline$\Delta S P 500_{t-3}$ & $\begin{array}{l}1.176 \\
(6.761)\end{array}$ & & & $\begin{array}{c}2.181 \\
(7.656)\end{array}$ & $\begin{array}{l}1.333 \\
(8.136)\end{array}$ & & $\begin{array}{c}2.258 \\
(8.560)\end{array}$ \\
\hline$\Delta N E E R_{t}^{U S D}$ & & $\begin{array}{c}1.460 \\
(13.543)\end{array}$ & & $\begin{array}{c}0.501 \\
(14.194)\end{array}$ & & $\begin{array}{l}-7.380 \\
(9.642)\end{array}$ & $\begin{array}{c}-6.627 \\
(10.375)\end{array}$ \\
\hline$\Delta N E E R_{t-1}^{U S D}$ & & $\begin{array}{c}-9.874 \\
(14.237)\end{array}$ & & $\begin{array}{l}-10.421 \\
(14.987)\end{array}$ & & $\begin{array}{c}-9.079 \\
(11.496)\end{array}$ & $\begin{array}{c}-8.193 \\
(12.482)\end{array}$ \\
\hline$\Delta N E E R_{t-2}^{U S D}$ & & $\begin{array}{c}-9.648 \\
(11.374)\end{array}$ & & $\begin{array}{c}-6.532 \\
(13.061)\end{array}$ & & $\begin{array}{c}-6.998 \\
(12.593)\end{array}$ & $\begin{array}{c}-4.436 \\
(14.156)\end{array}$ \\
\hline$\Delta N E E R_{t-3}^{U S D}$ & & $\begin{array}{l}6.568 \\
(9.214)\end{array}$ & & $\begin{array}{c}9.603 \\
(8.027)\end{array}$ & & $\begin{array}{c}4.550 \\
(13.186)\end{array}$ & $\begin{array}{c}6.332 \\
(10.237)\end{array}$ \\
\hline$\Delta$ Stock $k_{t}^{C H N}$ & & & $\begin{array}{c}-11.013 \\
(8.607)\end{array}$ & & $\begin{array}{l}-11.816 \\
(9.880)\end{array}$ & $\begin{array}{r}-11.598 \\
(8.704)\end{array}$ & $\begin{array}{l}-12.101 \\
(9.971)\end{array}$ \\
\hline$\Delta S t o c k_{t-1}^{C H N}$ & & & $\begin{array}{l}-1.079 \\
(4.126)\end{array}$ & & $\begin{array}{l}-1.606 \\
(4.221)\end{array}$ & $\begin{array}{l}-1.718 \\
(4.016)\end{array}$ & $\begin{array}{l}-1.997 \\
(4.027)\end{array}$ \\
\hline$\Delta$ Stock $_{t-2}^{C H N}$ & & & $\begin{array}{c}5.715 \\
(4.092)\end{array}$ & & $\begin{array}{c}4.845 \\
(3.686)\end{array}$ & $\begin{array}{c}4.636 \\
(4.114)\end{array}$ & $\begin{array}{c}3.901 \\
(3.437)\end{array}$ \\
\hline$\Delta S t o c k_{t-3}^{C H N}$ & & & $\begin{array}{c}2.007 \\
(2.820)\end{array}$ & & $\begin{array}{l}1.476 \\
(3.330)\end{array}$ & $\begin{array}{c}2.111 \\
(3.011)\end{array}$ & $\begin{array}{c}1.606 \\
(3.544)\end{array}$ \\
\hline Constant & $\begin{array}{c}-0.041 \\
(0.043) \\
\end{array}$ & $\begin{array}{l}-0.037 \\
(0.041)\end{array}$ & $\begin{array}{l}-0.027 \\
(0.042)\end{array}$ & $\begin{array}{c}-0.041 \\
(0.040) \\
\end{array}$ & $\begin{array}{l}-0.029 \\
(0.037)\end{array}$ & $\begin{array}{l}-0.027 \\
(0.039)\end{array}$ & $\begin{array}{l}-0.029 \\
(0.035)\end{array}$ \\
\hline Observations & 158 & 158 & 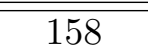 & 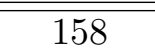 & 158 & 158 & 158 \\
\hline F test & 0.463 & 0.458 & 0.974 & 0.442 & 0.989 & 0.921 & 0.741 \\
\hline F prob & 0.708 & 0.712 & 0.407 & 0.849 & 0.434 & 0.482 & 0.671 \\
\hline$R^{2}$ & 0.00 & 0.00 & 3.32 & 0.00 & 1.24 & 1.26 & 0.00 \\
\hline
\end{tabular}

Notes: explanatory variables are in log-differences; the China stock index is the Shanghai stock market index. T-stats reported in parenthesis below coefficients and computed based on HAC standard errors. *** $p<0.01, * * p<0.05,{ }^{*} p<0.1$

in the future. The sequence $\left\{\beta^{k}\right\}_{k=0}^{12}$ is then the (non-linear) impulse response of variable $y$ to an innovation in $\hat{S}$. $\beta^{k}$ can be estimated with linear regressions using HAC standard errors, as residuals of Equation (3.1) are autocorrelated by construction (see Newey and West (1987) and Jordà (2005)). It has been shown that local projection estimates suffer from larger uncertainty than VARs (Kilian and Kim (2011)). In addition, developments not directly captured by the 3-T Index might impact the dependent variable. For these reasons, we include the lag of the US 2-year yield, the VIX and the US Citigroup macroeconomic surprise index among the controls. These variables should indeed capture the effect that shocks in the US and world economy other 
than those to the -implied- US trade stance might exert onto financial markets.

One of the advantages of local projections is that they are piece-wise linear and, hence, easily scalable. Therefore, we scale the responses by the value of the index on the announcement of the 2018 Steel and Aluminum tariff, so that our results can be interpreted as the reaction of financial markets to that specific announcement. The data sample spans from the US President election in November 2016 to November $2019^{28}$.
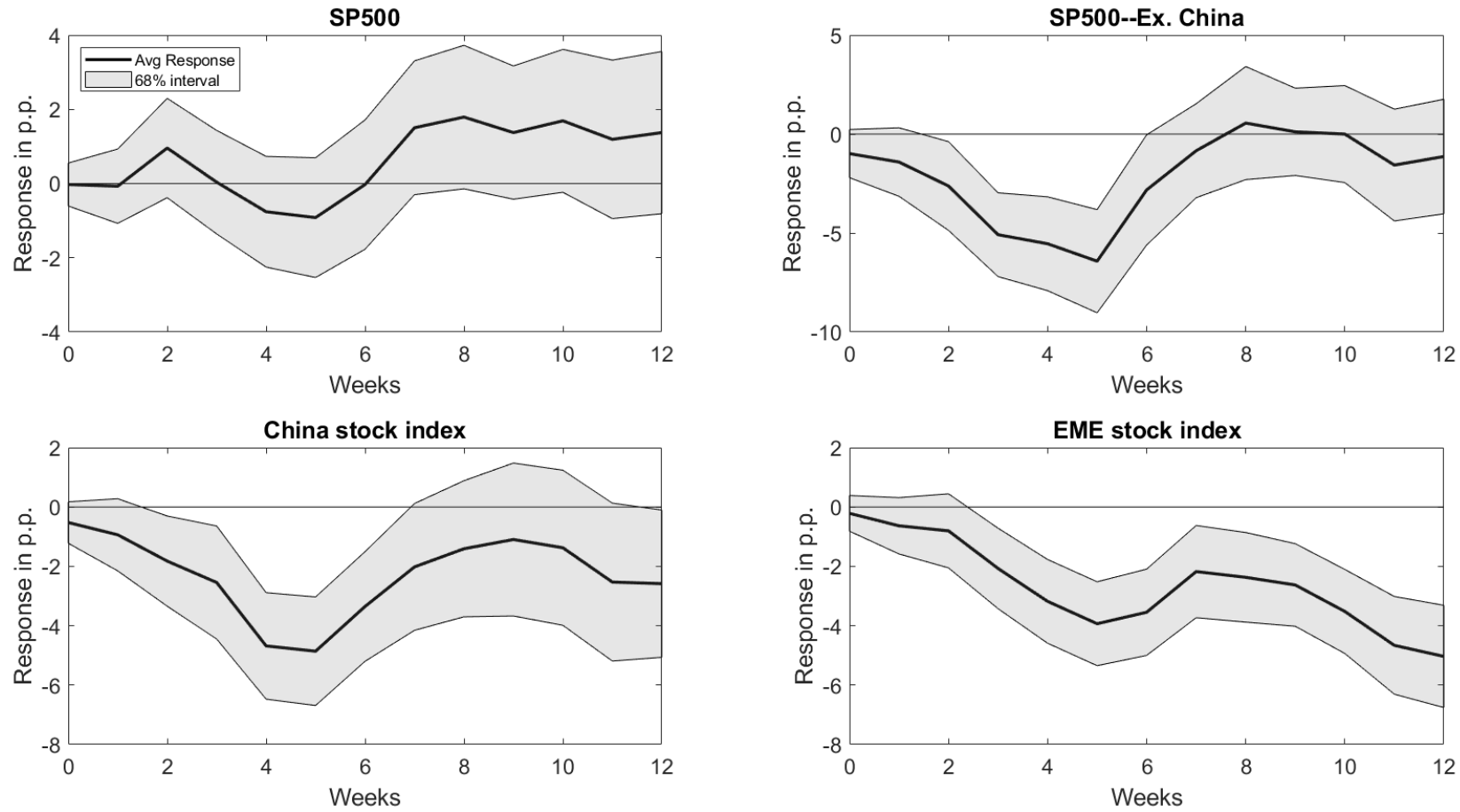

Figure 7: Response of stock market indices to the 2018 steel and aluminium tariff announcement. Source: Haver Analytics and authors' calculations.

Notes: We use the Shanghai stock market index as proxy for the stock index of China. The subindex of S\&P 500 exposed to China is computed including in the S\&P 500 only those firms that generate at least $10 \%$ of revenues from China.

\section{Stock indices}

A trade tension shock comparable to the 2018 Steel and Aluminum tariff announcement exerts a non significant impact on the US stock market as proxied by the S\&P 500 (Figure 7). However, the shock has a sizeable effect on stocks of US companies exposed to Chinese demand, which is in line with the evidence provided by part of the existing literature (Amiti et al. (2020) ${ }^{29}$. Those stocks indeed depreciate by around $5 \%$ in a four-week window. The Chinese stock market reacts in a very similar way, with the Shanghai stock index depreciating by $6 \%$ four weeks after the shock. Figure 7 also suggests that US-China tariffs announcements have significant spillovers

\footnotetext{
${ }^{28}$ Our results are robust to a number of additional checks that are presented in Section 3.1.

${ }^{29}$ We use here a sub-index of the S\&P 500 including only shares of companies that have at least $10 \%$ of their revenues originating from China.
} 
to other EMEs, as the aggregate stock market index of emerging market depreciates by about $4 \%$ within four weeks and grows weaker in the following months.
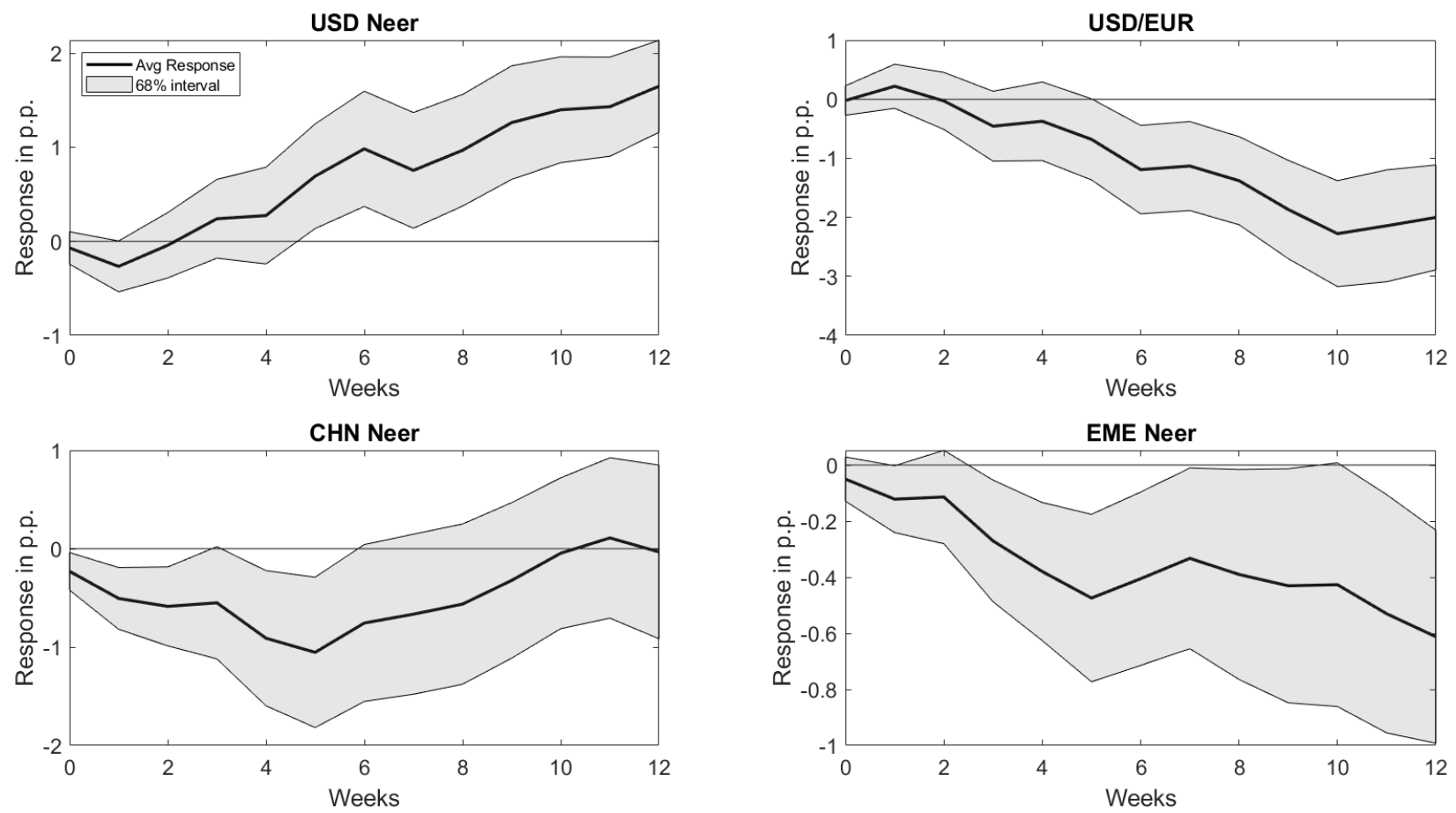

Figure 8: Response of exchange rates to the 2018 steel and aluminium tariff announcement. Source: Haver Analytics and authors' calculations.

\section{Exchange rates}

As to exchange rates, Figure 8 shows two main results. First, the US dollar appreciates six to twelve weeks after the trade tension shock, both in bilateral terms against the euro and in nominal effective terms ${ }^{30}$. Second, the Chinese renminbi and the synthetic EME exchange rate ${ }^{31}$ tend to depreciate at shorter horizons, while the reaction is muted over the longer-term. This latter evidence might depend on the fact that many EME currencies (including the renminbi) are either officially or de facto pegged to the US dollar.

Safe haven currencies, on the other hand, show a muted reaction to an increase in trade tensions (Figure 9). This result seems to suggest that financial market participants do not consider a tariff shock as a pure risk-off scenario, with investors selling risky asset to acquire safe securities. On the contrary, the reaction of exchange rates suggests a change in expectations over the international economic outlook and trade. Investors anticipate the slowdown in EMEs economic activity, with a subsequent reduction in trade flows, and consequently rebalance their portfolios. These dynamics trigger an appreciation of the US dollar, in that most of these

\footnotetext{
${ }^{30}$ We use the bilateral USD/EUR exchange rate as this is the most liquid exchange rate market in the world (Bank for International Settlements (2019)).

${ }^{31}$ Specifically, this is the J.P. Morgan EME nominal effective exchange rate index.
} 
currencies are actively traded against the $\mathrm{USD}^{32}$.
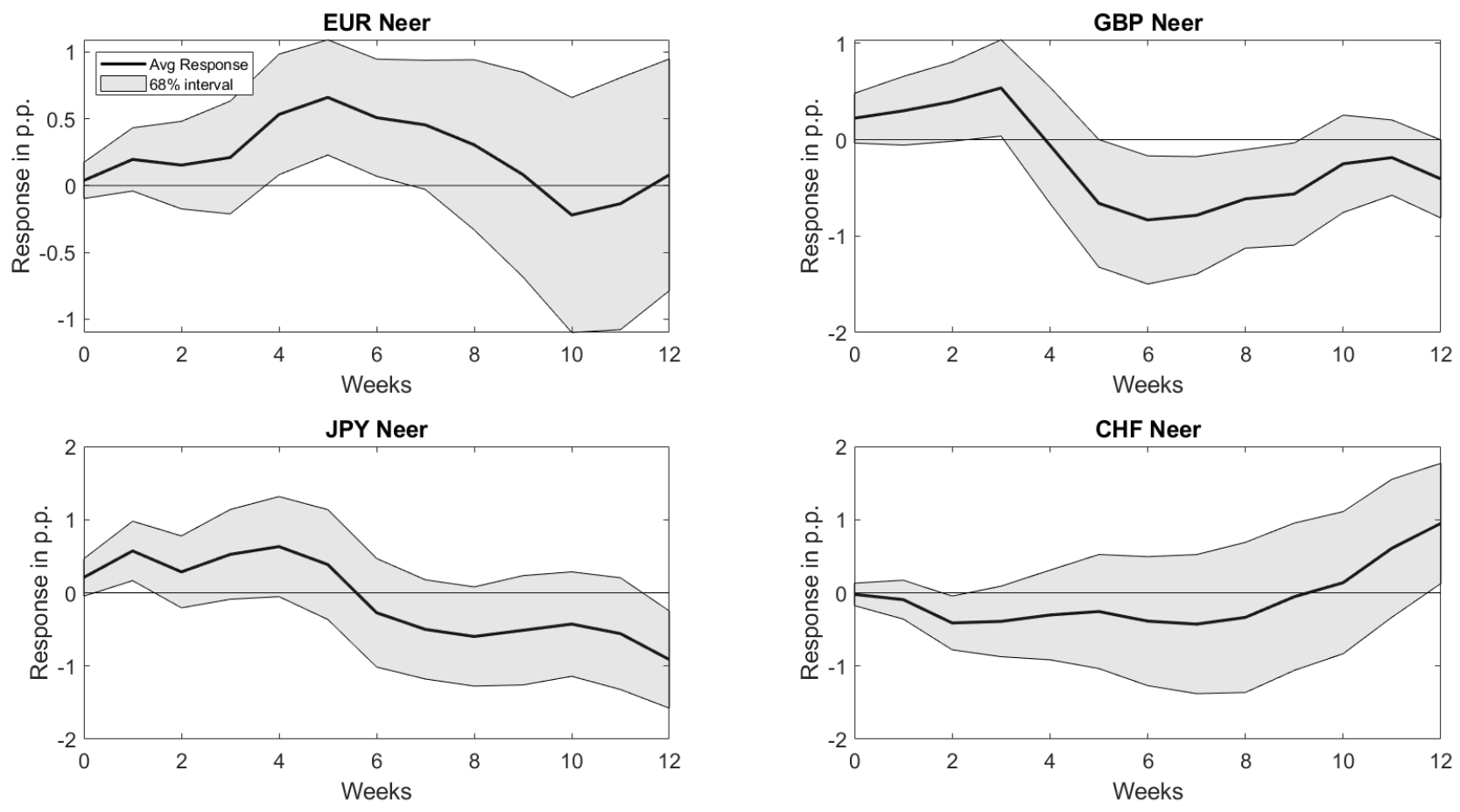

Figure 9: Response of safe haven currencies to the 2018 steel and aluminium tariff announcement.

Source: Haver Analytics and authors' calculations.

\section{Bond markets}

The estimated impact on bond markets suggests that financial agents do not read trade shocks as global risk shocks, but rather as changes to expectations on future economic performance (Figure 10). Results indeed highlight a very muted reaction of both US 10-year yields, which even increase at longer horizons, and the Chinese 10-year yield. This is inconsistent with a global risk shock that should trigger a portfolio rebalancing towards safe assets (i.e. US bonds), and consequently decrease their yields. Meanwhile, both the Shanghai government bond total return index and the EMBI+ index contract, which might be due to an increase in demand of these assets on the part of international investors. Coupled with the reaction of stock indices (Figure 10), these findings show that trade tension shocks provoked a portfolio rebalancing effect within China and, more generally, emerging markets, with investors selling stocks and buying bonds. This behaviour is more consistent with a shift in expectations towards lower profitability of EME companies due to a contraction of their foreign trade. Finally, as several emerging market bonds are denominated in US dollar, the contraction in the EMBI+ index is compatible with the US dollar appreciation.

\footnotetext{
${ }^{32}$ See Bank for International Settlements (2019).
} 

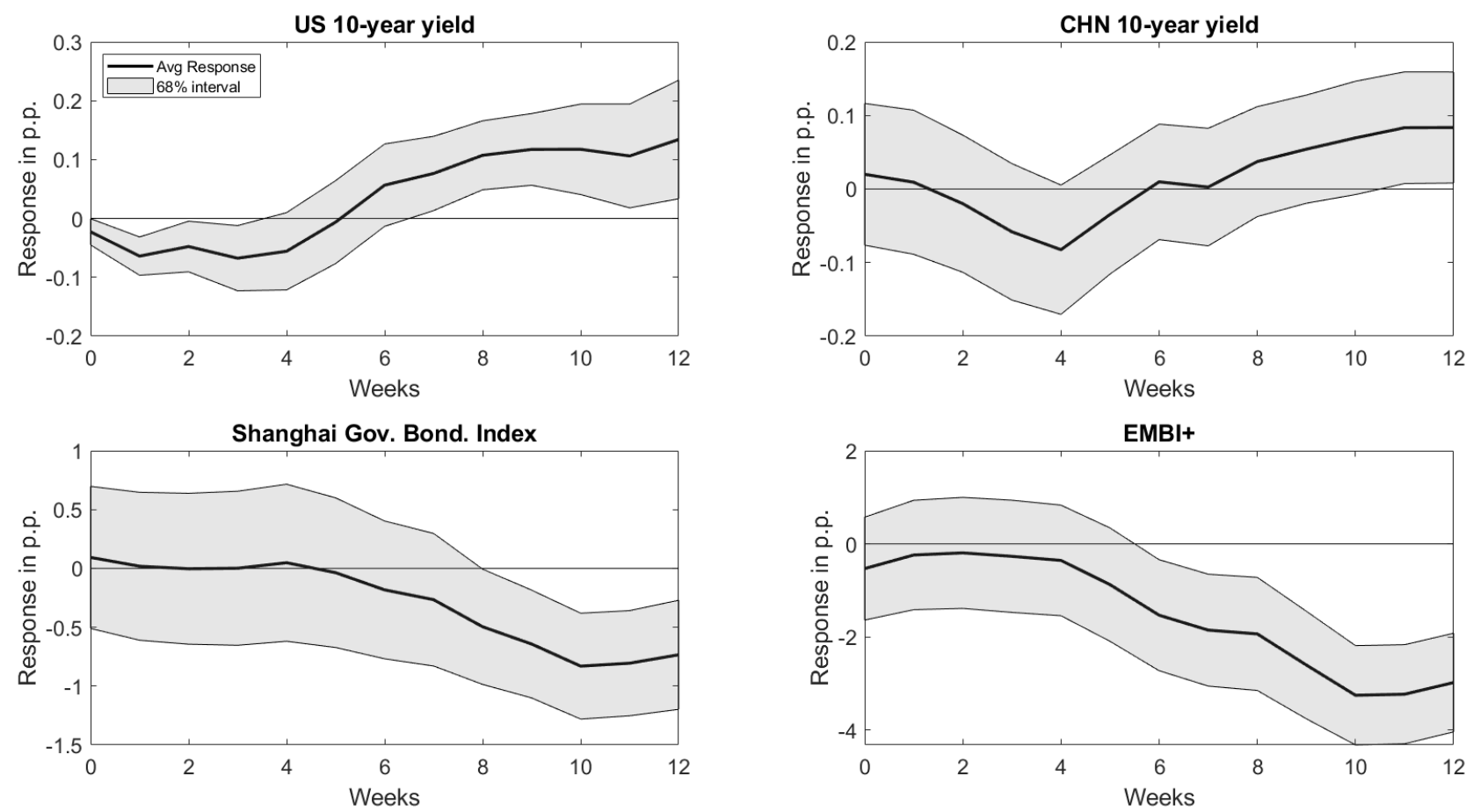

Figure 10: Response of bond indices to the 2018 steel and aluminium tariff announcement. Source: Haver Analytics and authors' calculations.

\section{Discussion}

Market reactions to a heightening of trade tensions is different from the reaction to rising global risk. Global risk shocks have negative effects on the US stock market, contract US yields in the wake of capital flows to the United States and lead to a dollar appreciation (Caballero and Kamber (2019)). At the same time, emerging market bond spreads increase, due to a devaluation of EMEs fixed-income assets (Akıncı (2013)).

Estimates of Equation (3.1) deliver quite different conclusions. While an increase in trade tension still triggers an appreciation of the US dollar, US sovereign bond yields do not move significantly and aggregate stock market indices remain broadly stable. However, the stocks of US companies exposed to China face a strong devaluation in the short-to-medium-run. As concerns the foreign exchange rate markets, currencies of countries that are more exposed to trade tensions depreciate, whereas safe haven currencies do not react. Moreover, EMEs do not seem to experience a net capital outflow, but rather a rebalancing between portfolio equity and debt, as indicated by the contraction in bond yields. This collection of results show that financial markets do not react to an increase in trade tension as they would when facing a global risk shock ${ }^{33}$.

Our results are indeed more aligned with the findings of standard economic models analyzing the impact of protectionism. When trade tensions rise, output contracts as trade is jeopardized.

\footnotetext{
${ }^{33}$ See Ioannou et al. (2020) for estimates of global risk aversion shocks.
} 
This is anticipated by investors, which then dis-invest from companies that might be hit harder by the shock, i.e. those companies operating in the countries and regions potentially targeted by the restrictive trade measures.

\subsection{Robustness checks}

We additionally perform several robustness checks on our baseline specification. Notably, we augment Equation (3.1):

$$
y_{t+k}=\alpha+\beta^{k} \hat{S}_{t}+\delta y_{t-1}+\Gamma^{\prime} X_{t}+\Xi^{\prime} G_{t}+\varepsilon_{t}
$$

where $G$ is a matrix of additional control variables. First, we include a time-trend to account for an unobserved component that might affect both the dependent variable and the 3T-Index. Figure B.2 reports the impulse responses for this extended model, which are broadly in line with the baseline estimates: following a positive trade tension shock, stock indices contract in EMEs, the US dollar appreciates and EMEs currencies depreciate. There are not significant effects on safe haven currencies and the EMBI+ total return index goes down, thus signalling the presence of portfolio re-balancing within EMEs. However, differently from the baseline results, the S\&P500 significantly increases over the longer-term, which is in line with expectations for improvements in US real activity triggered by trade diversion from EMEs.

In a further check, we alternatively include two lags of controls and one lag of the 3-T Index in $G$, in order to account for persistence in the data. Figure B.3 and Figure B.4 present the impulse response functions under the two alternative specifications: results are not significantly different from the baseline.

Finally, we check for the presence of some systematic factors in the 3T-Index that are orthogonal to market data, which would potentially generate an omitted-variable bias in the estimates of $\left\{\beta^{i}\right\}_{i=0}^{K}$ in Equation (2.4). We can filter-out these components by estimating an auxiliary $\operatorname{AR}(1)$ process $^{34}$ :

$$
\hat{S}_{t}=\alpha+\varrho \hat{S}_{t-1}+\eta_{t}
$$

where $\hat{S}_{t}$ is the 3 -T Index. We then take the estimated residuals $\hat{\eta}_{t}$ as the proxy for the trade tension shock in Equation (3.1). Figure B.5 reports the results, which are again broadly in line

\footnotetext{
${ }^{34}$ Assume that the variable $Y$ depends on a latent factor $S$ which has a persistent functional form. Formally: $Y_{t}=\alpha+\beta S_{t}+\varepsilon_{t}^{1}$ and $S_{t}=\gamma+\rho S_{t-1}+\varepsilon_{t}^{2}$, where $\varepsilon_{t}^{1}$ and $\varepsilon_{t}^{2}$ are two error terms. The equation can be rewritten as: $Y_{t}=\alpha+\beta\left[\gamma+\rho\left(\frac{Y_{t-1}}{\beta}-\frac{\alpha}{\beta}-\frac{\varepsilon_{t}^{1}-1}{\beta}\right)+\varepsilon_{t}^{2}\right]+\varepsilon_{t}^{1} \equiv \delta+\psi Y_{t-1}+\eta_{t}$ where $\delta=\alpha+\beta \gamma-\frac{\alpha}{\beta}, \psi=\beta \frac{\rho}{\beta}$ and $\eta_{t}=\beta \varepsilon_{t}^{2}+\varepsilon_{t}^{1}-\epsilon_{t-1}^{1}$. Fitting Equation (3.3) allows to extract $\eta_{t}$. When used in local projections $\eta_{t}$ delivers a clean (but inefficient) estimate of the impact of $\varepsilon_{t}^{1}\left(\left\{\beta^{i}\right\}_{i=0}^{K}\right.$ of Equation (3.1)) as $\varepsilon_{t}^{1}$ and $\varepsilon_{t}^{2}$ are uncorrelated and the Newey-West corrections control for the autocorrelation of $\eta_{t}$.
} 
with our baseline estimates.

\subsection{Contribution to financial market developments}

Section 3 shows that trade tension shocks have a sizeable impact on financial markets, which interpret them as a negative demand shock for the Chinese economy. However, those shocks might be rare events which do not systematically contribute to the volatility of stock prices and bonds. In other words, financial markets might have reacted to large trade announcements, but, on a daily basis, changes in the communication stance of the US government might have been largely ignored by agents.

We shed some light on this particular issue by estimating the contribution of the 3-T Index to the volatility of financial variables. Notably, we adopt the methodology proposed by Gorodnichenko and Lee (2019) to perform a forecast error variance decomposition (FEVD) of the variables of interest at different horizons ${ }^{35}$. For each dependent variable, the contribution of the $3-\mathrm{T}$ Index quantifies the share of the variance of that variable with is explained by our index at each horizon $k=0, \ldots, K$. Following Gorodnichenko and Lee (2019), we also apply a small sample bias correction to our estimates.

Figure 11 shows the FEVD for stock market indices at different horizons. ${ }^{36}$ As suggested by the impulse responses presented in Section 3, rising trade tensions do not contribute significantly to the volatility of US stocks. This is also true for the subsample of stocks exposed to Chinese demand, suggesting that US stock market reacts only to large changes in the trade stance of the US administration. EMEs stocks, on the contrary, seem to have been more affected by the increase in trade tensions between 2017 and 2019. The 3-T index indeed explains about $10 \%$ of monthly returns on the Chinese stock market, with a peak contribution of $15 \%$ over three months. More generally, the escalation of trade tensions between the US and China has contributed for around $10 \%$ to the volatility of EME markets in a 1 to 4 -month horizon.

Meanwhile, exchange rates of advanced economies are not significantly driven by rising tensions (Figure 12 and Figure B.6), a result that directly derives from the interpretation of trade tensions as demand shocks for China rather than as global risk shocks. In addition, the 3-T Index does not contribute significantly to the volatility Chinese renminbi either, most likely because the Chinese currency is de facto pegged to the US dollar. On the contrary, the FEVD of the EMEs exchange rates index, which includes several fully floating exchange rates, shows a significant contribution of trade tensions over a 3-month horizon (Figure 12).

\footnotetext{
${ }^{35}$ Gorodnichenko and Lee (2019) show that the contribution to the FEVD decomposition of a shock $x$ at horizon $k$ can be computed with local projections as the $R^{2}$ of an auxiliary regression of the local projection residuals at horizon $k$ on the sequence of shocks $\left\{x_{t+k}, \ldots, x_{t}\right\}$.

${ }^{36}$ The FEVD is computed on the full sample 2017-2019.
} 

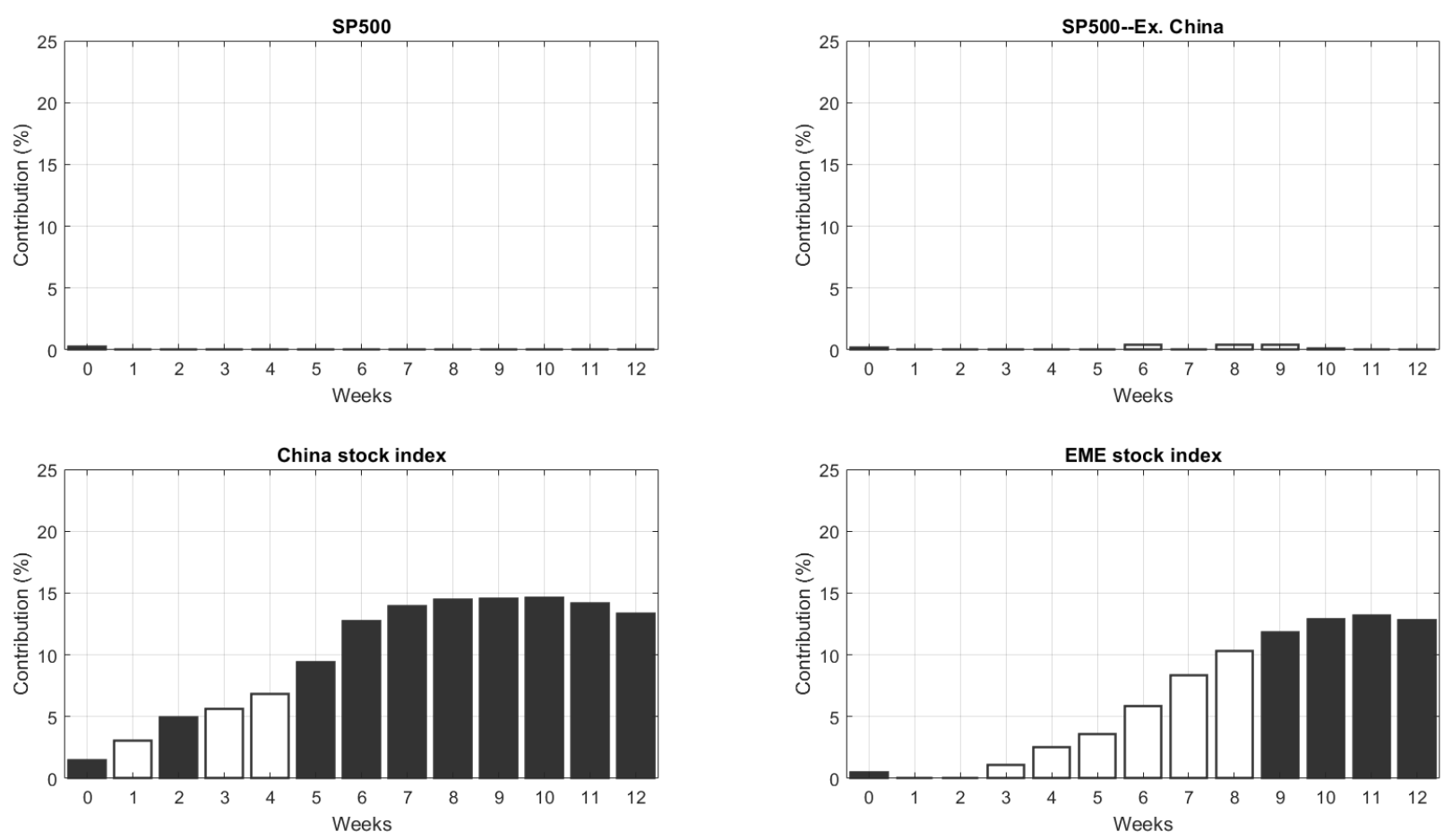

Figure 11: Contribution of trade tensions shocks to the FEVD of stock markets between 2017 and 2019.

Notes: White bars indicate contributions that are not statistically different from 0 at the $68 \%$ confidence level.

Source: Haver Analytics and authors' calculations.

Finally, the 3-T Index contributes little to the FEVD of 10-year yields, both in the US and Asia, which is in line with the absence of safe haven flows (Figure B.7). Rising trade tensions, instead, contribute to the volatility of the Shanghai government bond index, which is a composite of Chinese government securities of different maturities. This suggests that the escalation between the US and China have affected the short-end of the yield curve in emerging markets.

\section{Conclusion}

This paper proposes a novel identification approach to assess the impact that rising trade tensions have on financial markets. Notably, we take into consideration those announcements on the US-China trade dispute that were made on social media and we shoe that they were largely unanticipated by markets. Given this, we use machine learning tools to quantify the degree of "protectionism" of Twitter ${ }^{\circledR}$ posts related to the Sino-America trade tensions. We show that the constructed measures (3-T Index) is exogenous to financial markets developments and we use it in local-projection regressions to assess how global markets react to changes in trade tensions.

Our results show that rising trade tensions lead to a contraction of stock valuation in China 

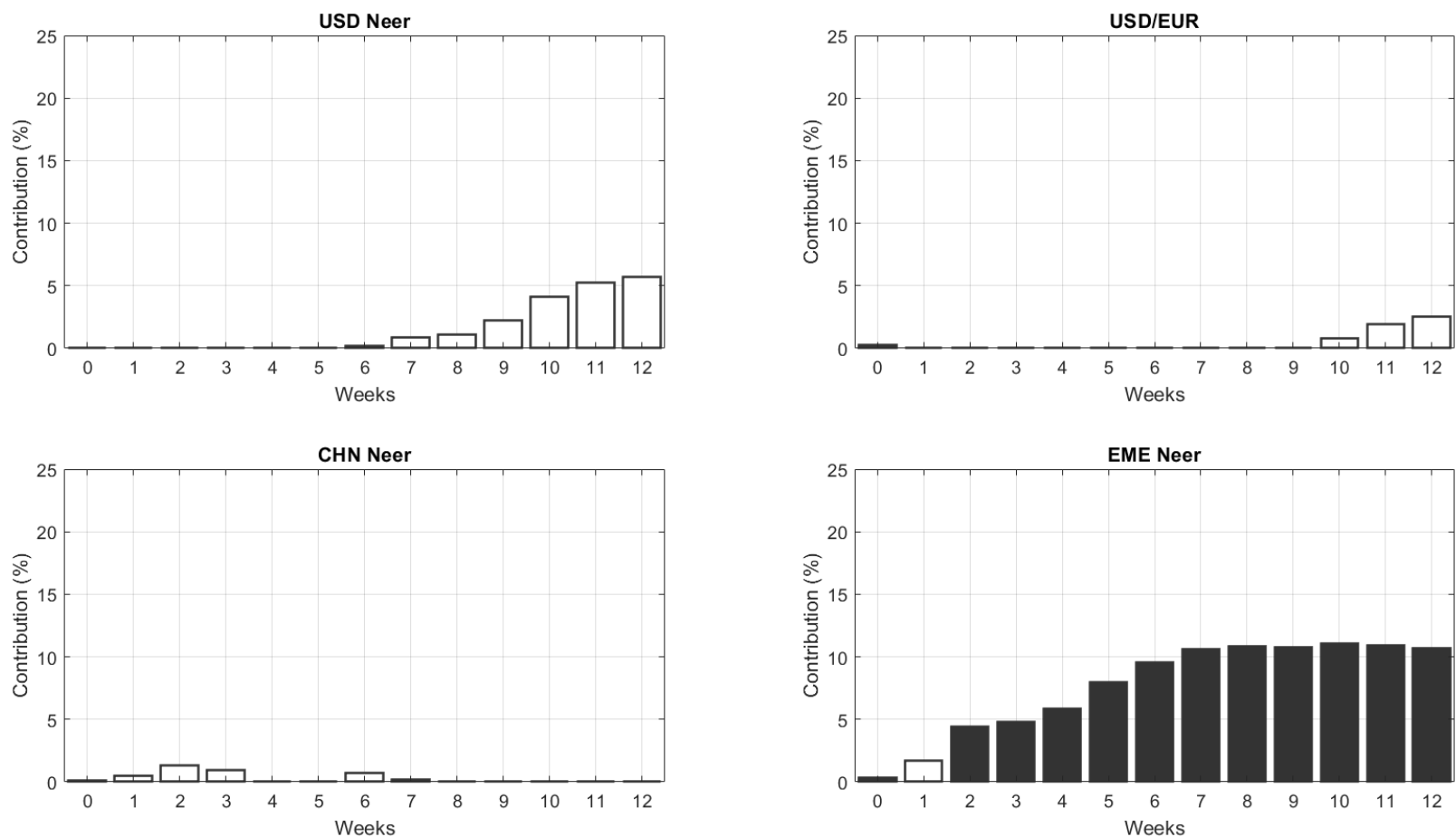

Figure 12: Contribution of trade tensions shocks to the FEVD of exchange rates between 2017 and 2019.

Notes: White bars indicate contributions that are not statistically different from 0 at the $68 \%$ confidence level. Source: Haver Analytics and authors' calculations.

and EMEs. That contraction is economically significant and explains 10 to $15 \%$ of the volatility of those stock indices. US stocks instead are largely unaffected, except for those companies whose revenues heavily depend on trade with China. Moreover, the US dollar appreciates, EMEs exchange rates depreciate, while safe have currencies do not react. Finally, on bond markets, there are no signs of safe have flows to the US, while in EMEs there is evidence of a portfolio re-balancing between stocks and bonds.

These findings, especially the lack of safe-haven effects, challenge the interpretation of trade tensions as global risk aversion shocks. On the contrary, results suggest that financial markets rather interpret trade tensions as a more standard negative demand shock for China, which, in turn, might help explain the contraction in global output observed in 2019. 


\section{References}

[1] Acemoglu, D., Autor, D., Dorn, D., Gordon, H. H., and Price, B. "Import competition and the great us employment sag of the 2000s". Journal of Labor Economics, 34(51):141-198, 2016 .

[2] Akıncı, O. "Global financial conditions, country spreads and macroeconomic fluctuations in emerging countries". Journal of International Economics, 91(2):358-371, 2013.

[3] Amiti, M., Kong, S. H., and Weinstein, D. "The effect of the u.s.-china trade war on u.s. investment". NBER Working Papers, (27114), 2020.

[4] Autor, D. H., Dorn, D., and Gordon, H. H. "The china shock: Learning from labor-market adjustment to large changes in trade". Annual Review of Economics, 8(1):205-240, 2016.

[5] Baker, S. R. and Bloom, N. "Does uncertainty reduce growth? using disasters as natural experiments". NBER Working Papers, (19475), 2013.

[6] Baker, S. R., Bloom, N., and Davis, S. J. "Measuring economic policy uncertainty". The Quarterly Journal of Economics, 131(4), 2016.

[7] Bank for International Settlements. "Triennial central bank survey of foreign exchange and over-the-counter (otc) derivatives markets in 2019". Technical report, BIS, 2019.

[8] Barattieri, A., Cacciatore, M., and Ghironi, F. "Protectionism and the business cycle". NBER Working Papers, 24353, 2018.

[9] Bekaert, G., Hoerova, M., and Lo Duca, M. "Risk, uncertainty and monetary policy". Journal of Monetary Economics, 60(7):771-788, 2013.

[10] Berthou, A., Jardet, C., Siena, D., and Ursula, S. "Costs and consequences of a trade war: a structural analysis". Rue de la Banque, Banque de France, 72, 2018.

[11] Bianchi, F., Kung, H., and Kind, T. "Threats to central bank independence: Highfrequency identification with twitter". Technical report, National Bureau of Economic Research, 2019.

[12] Bloom, N. "The impact of uncertainty shocks". Econometrica, 77(3):623-685, 2009.

[13] Bollen, J., Mao, H., and Zeng, X. "Twitter mood predicts the stock market". Journal of Computational Science, 2(1):1-8, 2011.

[14] Caballero, R. and Kamber, G. "The global impact of risk-off shocks". Bank for International Settlements (ed.), Asia-Pacific fixed income markets: evolving structure, participation and pricing, 102:17-23, 2019.

[15] Caggiano, G., Castelnuovo, E., and Groshenny, N. "Uncertainty shocks and unemployment dynamics in u.s. recessions". American Economic Review, 67:78-92, 2014.

[16] Caldara, D. and Iacoviello, M. "Measuring geopolitical risk". International Finance Discussion Papers, Board of Governors of the Federal Reserve System (U.S.), 1222, 2018.

[17] Caldara, D., Iacoviello, M., Molligo, P., Prestipino, A., and Raffo, A. "The economic effects of trade policy uncertainty". Technical report, International Finance Discussion Papers 1256, 2019. 
[18] Chung, C. and Pennebaker, J. "The psychological functions of function words". In Fiedler, K., editor, Frontiers of social psychology. Social communication, page 343-359. Psychology Press, 2004.

[19] Congressional Research Service. "U.s. - china tariff actions by the numbers". Technical report, US Congress, 2019.

[20] Currie, J., Kleven, H., and Zwiers, E. "Technology and big data are changing economics: Mining text to track methods". Princeton University Working Papers, 2019.

[21] Da, Z., Engelberg, J., and Gao, P. "In search of attention". Journal of Finance, 66(5): 1461-1499, 2011.

[22] Eichengreen, B. "Trade policy and the macroeconomy". Mundell-Fleming Lecture 2017, 2017.

[23] Feenstra, R., Ma, H., and Xu, Y. "Us exports and employment". Journal of International Economics, 120(C):46-58, 2019.

[24] Feenstra, R. C. and Sasahara, A. "The 'china shock,' exports and u.s. employment: A global input-output analysis". Review of International Economics, 26(5):1053-1083, 2018.

[25] Fernández-Villaverde, J., Guerrón-Quintana, P., Rubio-Ramírez, J. F., and Uribe, M. "Risk matters: The real effects of volatility shocks". American Economic Review, 101(6):2530-61, 2011.

[26] Furceri, D., Ahmed Hannan, S., Ostry, J., and Rose, A. "Macroeconomic consequences of tariffs". NBER Working Papers, 25402, 2018.

[27] Gentzkow, M., Kelly, B., and Taddy, M. "Text as data". Journal of Economic Literature, $57(3): 535-574,2019$.

[28] Gholampour, V. and van Wincoop, E. "Exchange rate disconnect and private information: What can we learn from euro-dollar tweets?". Journal of international Economics, 119(C): 111-132, 2019.

[29] Gloe Dizioli, A. and van Roye, B. "Macroeconomic implications of increasing protectionism". ECB Economic Bulletin, 6, 2018.

[30] Gopinath, G. "The world economy: Synchronized slowdown, precarious outlook". IMF Blog, 2019.

[31] Gorodnichenko, Y. and Lee, B. "Forecast error variance decompositions with local projections". Journal of Business \& Economic Statistics, 2019.

[32] Hansen, S., McMahon, M., and Prat, A. "Transparency and deliberation within the fomc: a computational linguistic approach". The Quarterly Journal of Economics, 133(2):535-574, 2018 .

[33] Harberger, A. "The incidence of the corporation income tax". Journal of Political Economy, $70(3): 215-240,1962$.

[34] Hastie, T., Tibshirani, R., and Friedman, J. The Elements of Statistical Learning. Springer, 2009.

[35] Hutto, C. J. and Gilbert, E. "Vader: A parsimonious rule-based model for sentiment analysis of social media text". In ICWSM, 2014. 
[36] Ioannou, D., Pagliari, M. S., and Stracca, L. "The international impact of EMU deepening". ECB Mimeo, 2020.

[37] Jordà, O. "Estimation and inference of impulse responses by local projections". American Economic Review, 95(1):161-182, 2005.

[38] Jurado, K., Ludvigson, S., and Ng, S. "Measuring uncertainty". American Economic Review, 105(3):1177-1216, 2015.

[39] Ke, Z. T., Kelly, B., and Xiu, D. "Predicting returns with text data". NBER Working Papers, 26186, 2019.

[40] Kilian, L. and Kim, Y. J. "The review of economics and statistics". The Review of Economics and Statistics, 93(4):1460-1466, 2011.

[41] Leung, H. and Ton, T. "The impact of internet stock message boards on cross-sectional returns of small-capitalization stocks". Journal of Banking \& Finance, 55:37-55, 2015.

[42] Loughran, T. and McDonald, B. "When is a liability not a liability? textual analysis, dictionaries, and 10-ks". Journal of Banking \& Finance, 66(1):35-65, 2011.

[43] Meinen, P. "The effects of tariff hikes in a world of global value chains". ECB Economic Bulletin, 8, 2019.

[44] Newey, W. and West, K. "A simple, positive semi-definite, heteroskedasticity and autocorrelation consistent covariance matrix". Econometrica, 55(3):703-708, 1987.

[45] Ossa, R. "Trade wars and trade talks with data". American Economic Review, 104(12): 4104-46, 2014.

[46] Porter, M. F. et al. "An algorithm for suffix stripping.". Program, 14(3):130-137, 1980.

[47] Tibshirani, R. "Regression shrinkage and selection via the lasso". Journal of the Royal Statistical Society, 58(1):267-288, 1996.

[48] Tillmann, P. "Trump, twitter and treasuries". Contemporary Economic Policy, 38(3): 403-408, 2020.

[49] Werner, A. and Murray, F. "Is all that talk just noise? the information content of internet stock message boards". The Journal of Finance, 53(3):1259-1294, 2004.

[50] Wilson, T., Wiebe, J., and Hoffmann, P. "Recognizing contextual polarity in phraselevel sentiment analysis". Proceedings of Human Language Technology Conference and Conference on Empirical Methods in Natural Language Processing, 2005.

[51] Zou, H. and Hastie, T. "Regularization and variable selection via the elastic net". Journal of the Royal Statistical Society, 67(2):301-320, 2005. 


\section{Appendix}

\section{A Standardization and cleaning of the tweets}

Tweets (and retweets) by the US President are downloaded from the Trump Twitter Archive (http://www.trumptwitterarchive.com/) for the period January 2016 to November 2019. All special characters and numbers are removed. The remaining letters are converted to lowercase, common stop words are removed, and word endings standardized (stemmed) according to (46). Finally, words occurring only once in the entire sample, as well as single character words, are deleted. Tweets are then merged with identical timestamps (occurring in the same second).

This sample of cleaned tweets is narrowed down by keeping only those that feature one or several of the keywords China, trade, or tariff. From the training sample (Section 2), we include frequently occurring bigrams (two consecutive words forming a unit to retain their meaning). After these steps, the training sample features 662 unique words or bigrams which are used as regressors in the elastic net estimation.

\section{B Figures}

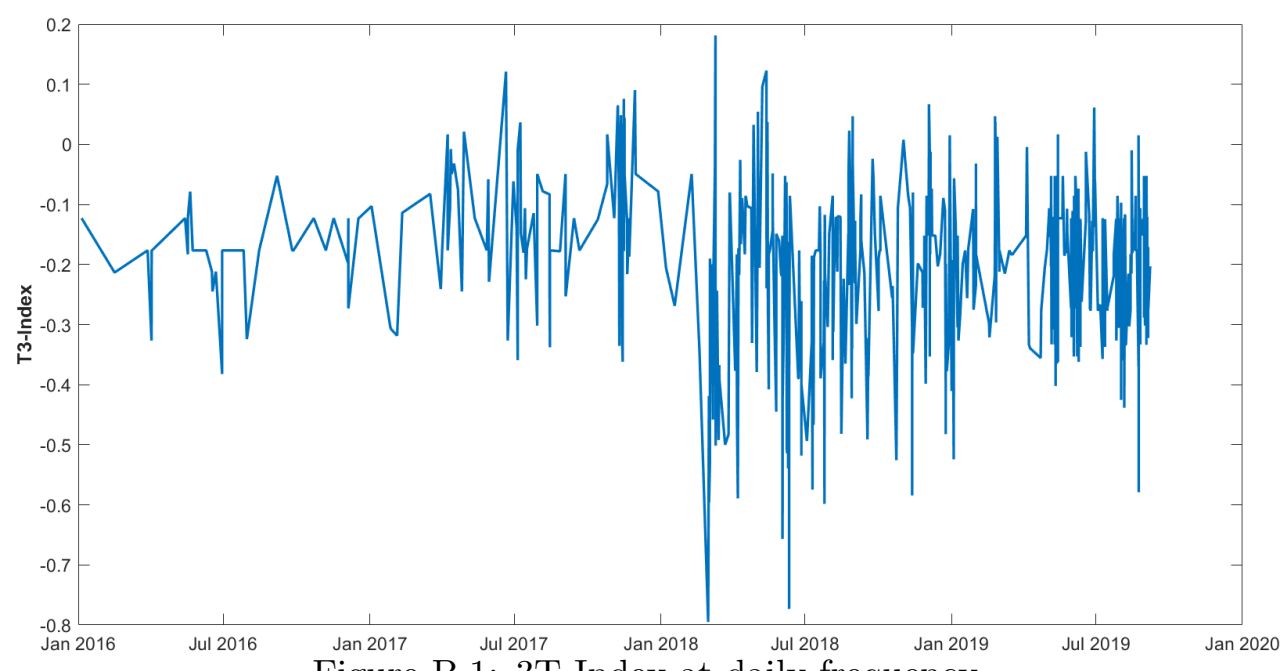

Figure B.1: 3T-Index at daily frequency 


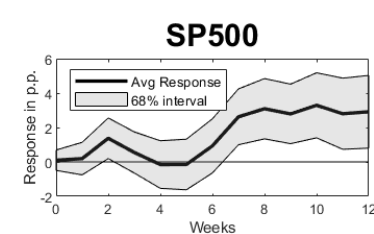

CHN Neer

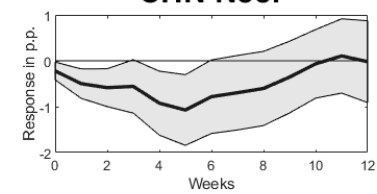

US 10-year yield

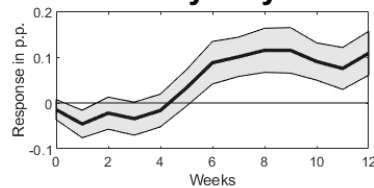

EUR Neer

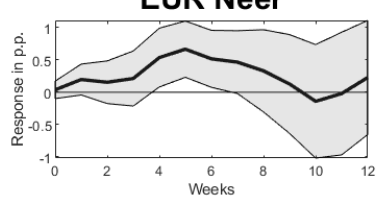

China stock index

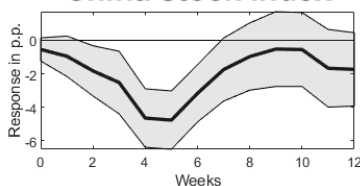

EME Neer

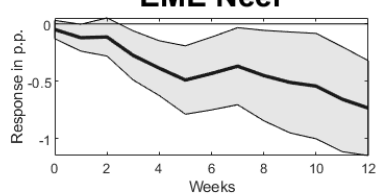

SP500--Ex. China

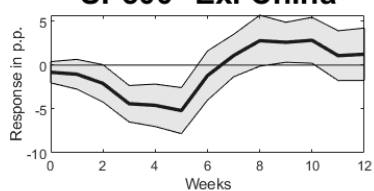

GBP Neer

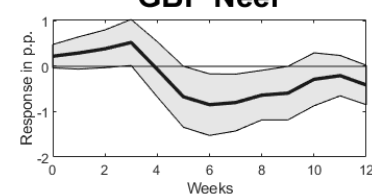

EME stock index

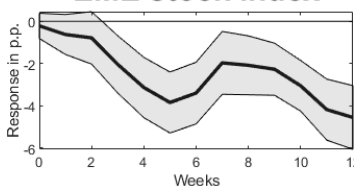

USD/EUR

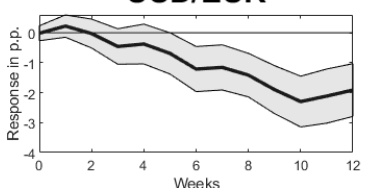

JPY Neer

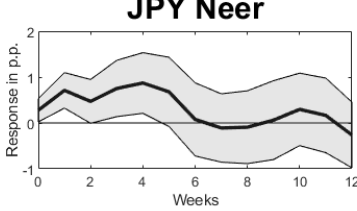

Shanghai Gov. Bond

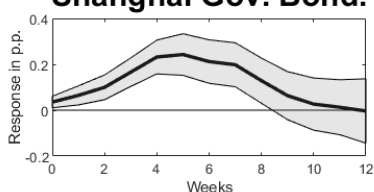

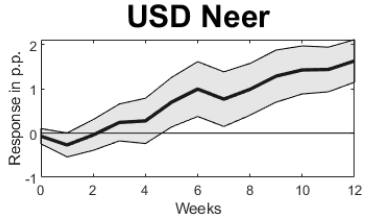

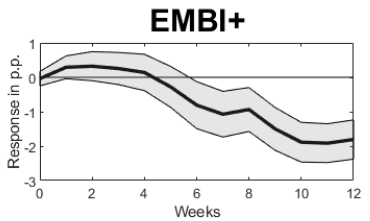

CHF Neer

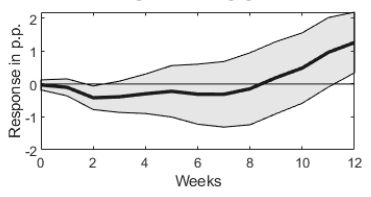

Figure B.2: IRFs to the 2018 steel and aluminium tariff announcement - full sample with time trend

Source: Haver Analytics and authors' calculations.

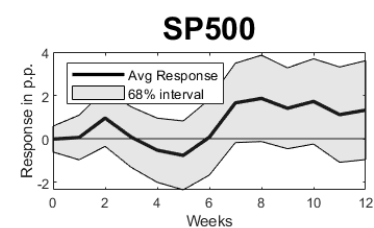

CHN Neer

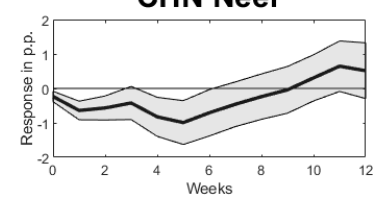

US 10-year yield

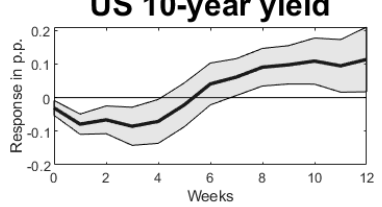

EUR Neer

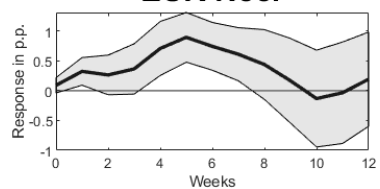

China stock index

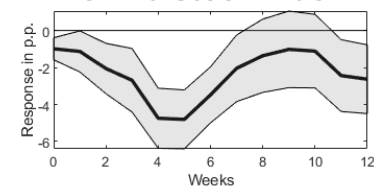

EME Neer

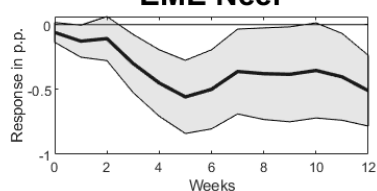

SP500--Ex. China

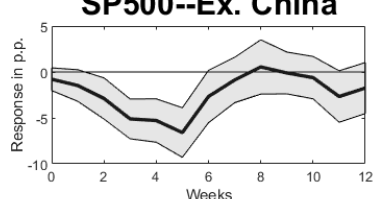

GBP Neer

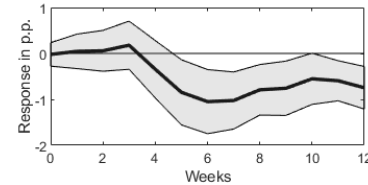

EME stock index

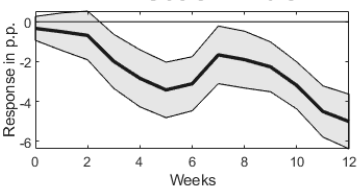

USD/EUR

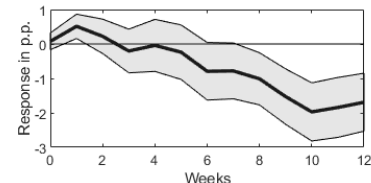

JPY Neer

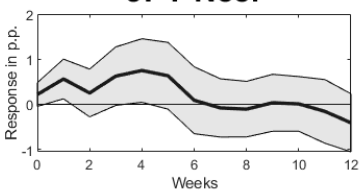

Shanghai Gov. Bond.

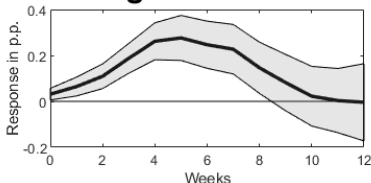

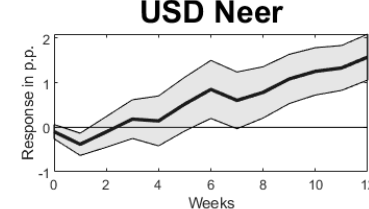

$\mathrm{EMBI+}$

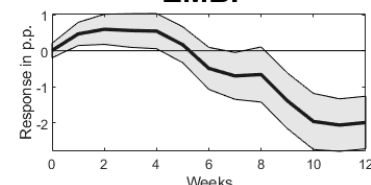

CHF Neer

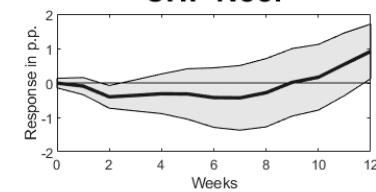

Figure B.3: IRFs to the 2018 steel and aluminium tariff announcement - full sample with 2 lags of controls and endogenous variable.

Source: Haver Analytics and authors' calculations. 


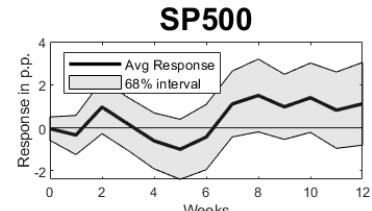

CHN Neer

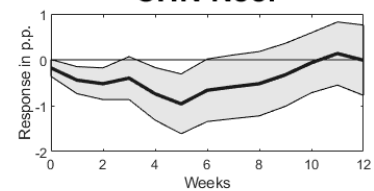

US 10-year yield

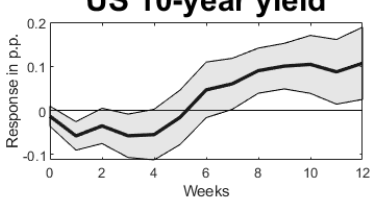

EUR Neer

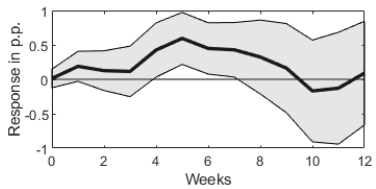

Figure B.4: IRFs to the 2018 steel and aluminium tariff announcement - full sample with 1 lag of the Index.

Source: Haver Analytics and authors' calculations.
EME Neer

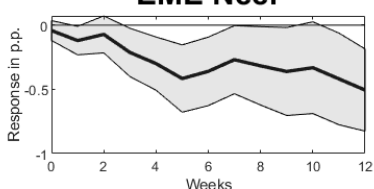

SP500--Ex. China

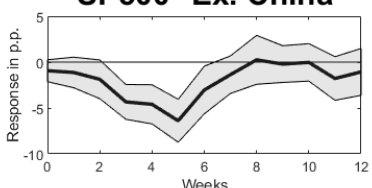

GBP Neer

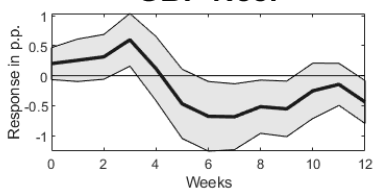

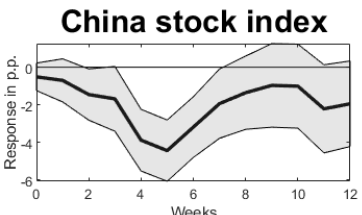

EME stock index

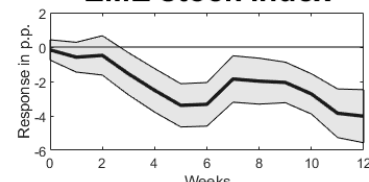

USD/EUR

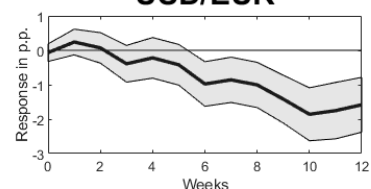

JPY Neer

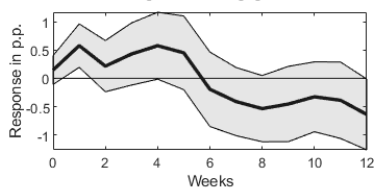

Shanghai Gov. Bond.

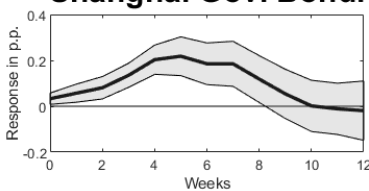

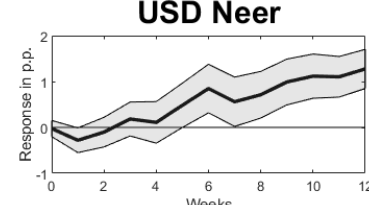

$\mathrm{EMBI+}$

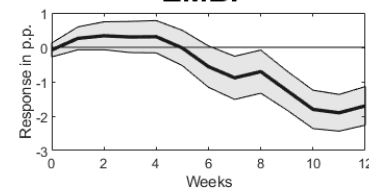

CHF Neer

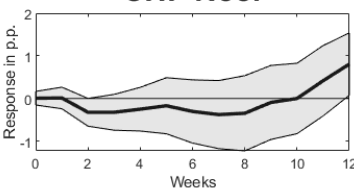



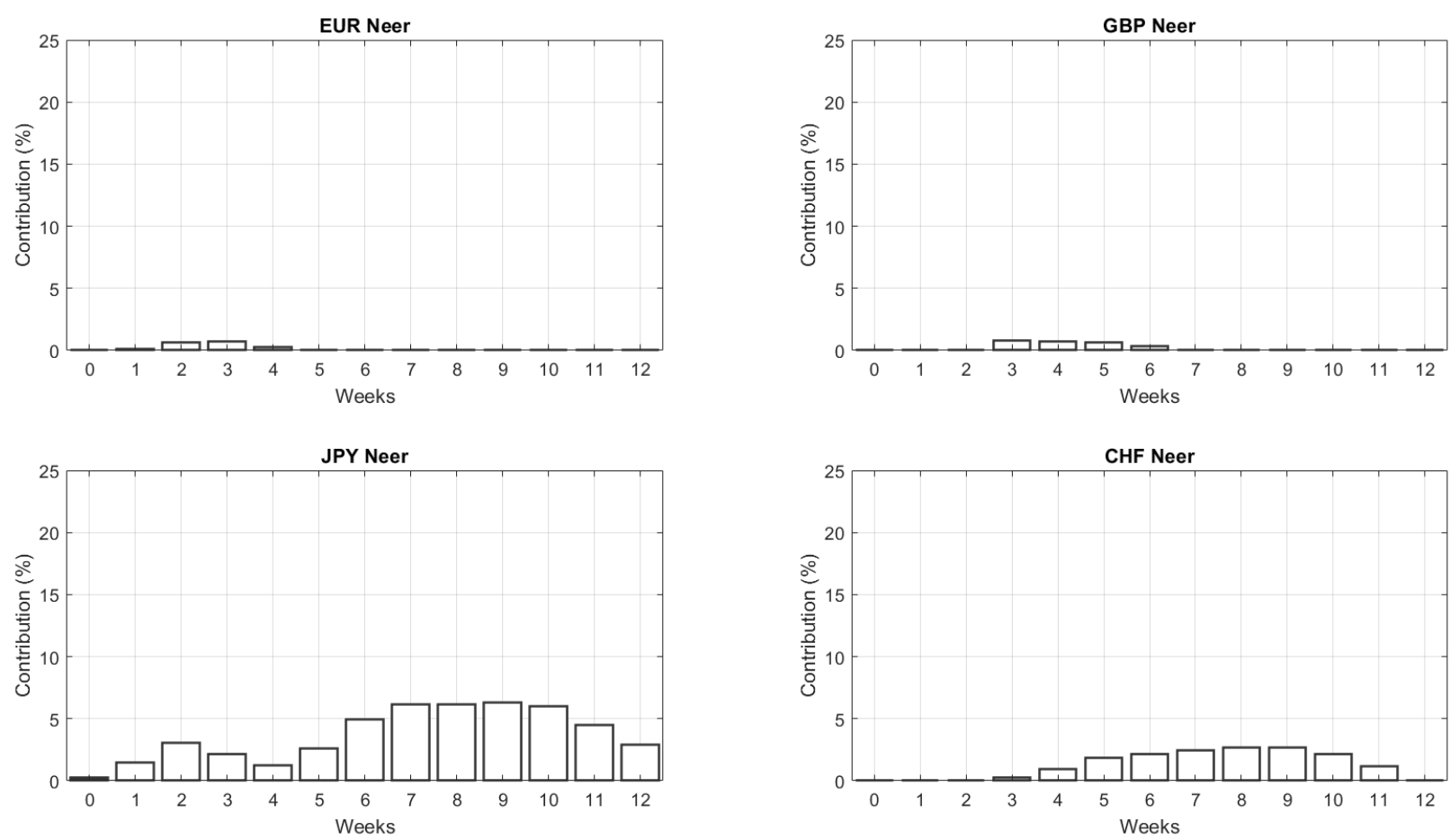

Figure B.6: Contribution of trade tensions shocks to the FEVD of safe haven exchange rates between 2017 and 2019.

Notes: White bars indicate contributions that are not statistically different from 0 at the $68 \%$ confidence level. Source: Haver Analytics and authors' calculations.
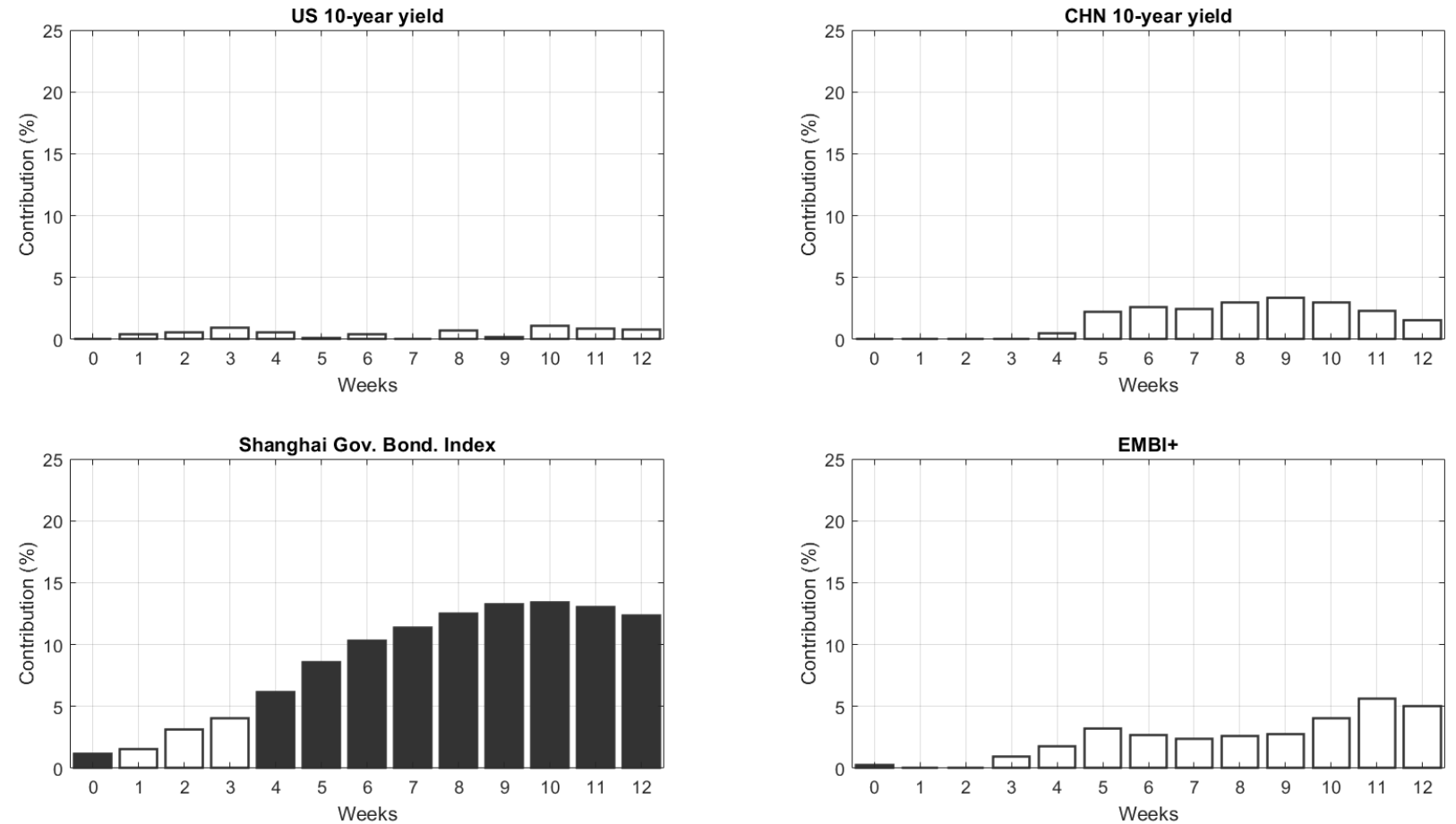

Figure B.7: Contribution of trade tensions shocks to the FEVD of bond yields between 2017 and 2019.

Notes: White bars indicate contributions that are not statistically different from 0 at the $68 \%$ confidence level. Source: Haver Analytics and authors' calculations. 


\section{B.1 Tables}

Table B.1: Trade war tweets included in the event study

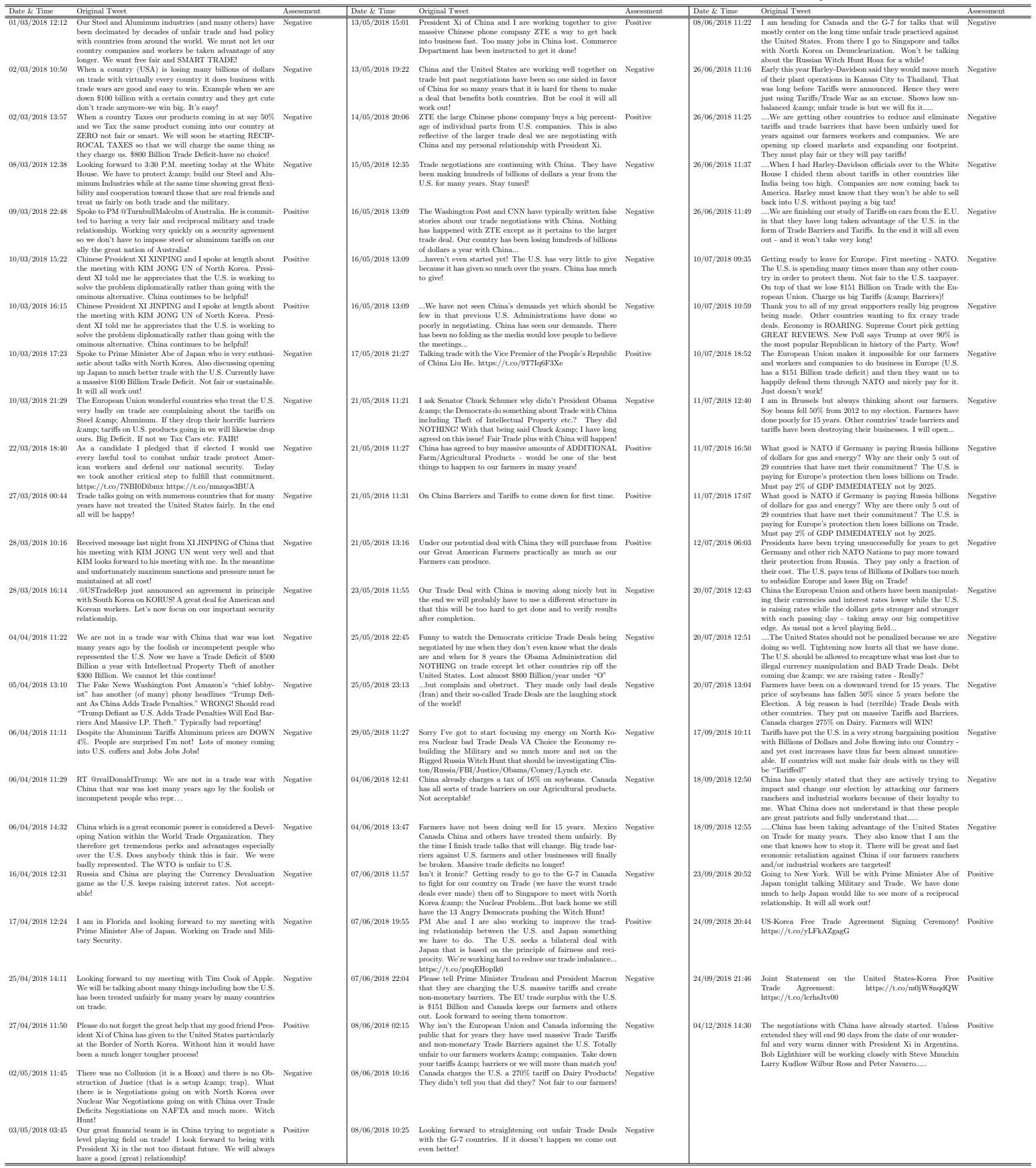


Table B.2: List of tweets used in the training sample

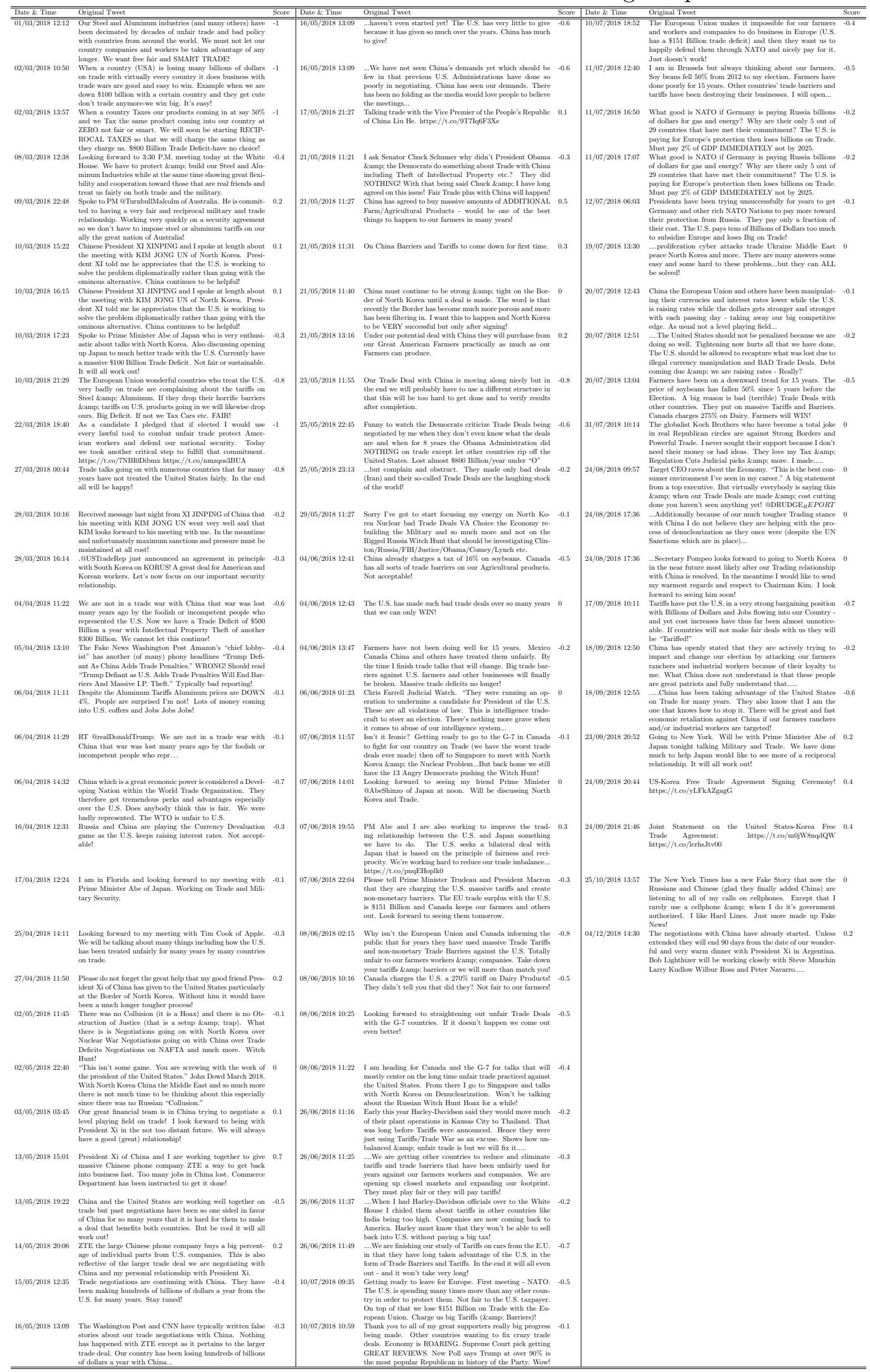


Table B.3: Selected words and loadings by elastic net algorithm, Equation (2.2)

\begin{tabular}{lc}
\hline \hline Word & Loading \\
\hline \hline advantag & -0.06667 \\
agreement & 0.049195 \\
anoth & -0.00874 \\
barrier & -0.01356 \\
billion & -0.09218 \\
charg & -0.04538 \\
countri & -0.15007 \\
deficit & -0.03529 \\
end & -0.09196 \\
even & -0.0222 \\
fair & -0.03681 \\
korea & 0.073555 \\
made & 0.027548 \\
much & 0.00242 \\
not & -0.06014 \\
pai & 0.012072 \\
presid & 0.07043 \\
relationship & 0.059126 \\
trade & -0.05362 \\
unfair & -0.1656 \\
us & -0.01003 \\
veri & -0.02898 \\
work & 0.090961 \\
worker & -0.13911 \\
xi & 0.069126 \\
year & -0.00401 \\
zte & 0.015077 \\
\hline \hline
\end{tabular}


Table B.4: Estimates from equation Equation (2.4) at weekly frequency

\begin{tabular}{|c|c|c|c|c|c|c|c|}
\hline $\begin{array}{l}\text { Dep. variable } \\
3 \text {-T Index (lev.) }\end{array}$ & $\begin{array}{l}\text { Model } \\
(1)\end{array}$ & $\begin{array}{l}\text { Model } \\
(2)\end{array}$ & $\begin{array}{c}\text { Model } \\
(3)\end{array}$ & $\begin{array}{l}\text { Model } \\
(4)\end{array}$ & $\begin{array}{l}\text { Model } \\
(5)\end{array}$ & $\begin{array}{l}\text { Model } \\
(6)\end{array}$ & $\begin{array}{l}\text { Model } \\
(7)\end{array}$ \\
\hline$\Delta S P 500_{t}$ & $\begin{array}{c}0.381 \\
(0.673)\end{array}$ & & & $\begin{array}{c}0.326 \\
(0.707)\end{array}$ & $\begin{array}{c}0.201 \\
(0.714)\end{array}$ & & $\begin{array}{c}0.186 \\
(0.733)\end{array}$ \\
\hline$\Delta S P 500_{t-1}$ & $\begin{array}{l}0.208 \\
(0.738)\end{array}$ & & & $\begin{array}{c}0.313 \\
(0.749)\end{array}$ & $\begin{array}{c}0.073 \\
(0.768)\end{array}$ & & $\begin{array}{l}0.156 \\
(0.786)\end{array}$ \\
\hline$\Delta S P 500_{t-2}$ & $\begin{array}{l}1.055 \\
(0.659)\end{array}$ & & & $\begin{array}{c}0.871 \\
(0.665)\end{array}$ & $\begin{array}{l}1.021 \\
(0.675)\end{array}$ & & $\begin{array}{c}0.889 \\
(0.693)\end{array}$ \\
\hline$\Delta N E E R_{t}^{U S D}$ & & $\begin{array}{l}-0.764 \\
(1.485)\end{array}$ & & $\begin{array}{l}-0.595 \\
(1.558)\end{array}$ & & $\begin{array}{l}-0.355 \\
(1.532)\end{array}$ & $\begin{array}{l}-0.260 \\
(1.575)\end{array}$ \\
\hline$\Delta N E E R_{t-1}^{U S D}$ & & $\begin{array}{c}0.959 \\
(1.416)\end{array}$ & & $\begin{array}{l}1.019 \\
(1.415)\end{array}$ & & $\begin{array}{l}1.010 \\
(1.495)\end{array}$ & $\begin{array}{c}0.793 \\
(1.472)\end{array}$ \\
\hline$\Delta N E E R_{t-2}^{U S D}$ & & $\begin{array}{l}-2.181 \\
(1.695)\end{array}$ & & $\begin{array}{l}-1.575 \\
(1.664)\end{array}$ & & $\begin{array}{l}-1.679 \\
(1.586)\end{array}$ & $\begin{array}{l}-1.321 \\
(1.612)\end{array}$ \\
\hline$\Delta$ Stock $_{t}^{C H N}$ & & & $\begin{array}{c}0.496 \\
(0.475)\end{array}$ & & $\begin{array}{c}0.541 \\
(0.510)\end{array}$ & $\begin{array}{c}0.503 \\
(0.479)\end{array}$ & $\begin{array}{l}0.524 \\
(0.516)\end{array}$ \\
\hline$\Delta$ Stock $_{t-1}^{C H N}$ & & & $\begin{array}{c}-0.144 \\
(0.488)\end{array}$ & & $\begin{array}{c}-0.382 \\
(0.548)\end{array}$ & $\begin{array}{c}-0.132 \\
(0.509)\end{array}$ & $\begin{array}{c}-0.362 \\
(0.560)\end{array}$ \\
\hline$\Delta$ Stock $_{t-2}^{C H N}$ & & & $\begin{array}{c}0.684 \\
(0.590)\end{array}$ & & $\begin{array}{c}0.442 \\
(0.615)\end{array}$ & $\begin{array}{c}0.592 \\
(0.590)\end{array}$ & $\begin{array}{c}0.394 \\
(0.616)\end{array}$ \\
\hline Constant & $\begin{array}{c}-0.135^{* * *} \\
(0.012)\end{array}$ & $\begin{array}{c}-0.131^{* * *} \\
(0.011)\end{array}$ & $\begin{array}{c}-0.131^{* * * *} \\
(0.011)\end{array}$ & $\begin{array}{c}-0.135^{* * *} \\
(0.012)\end{array}$ & $\begin{array}{c}-0.134^{* * *} \\
(0.011)\end{array}$ & $\begin{array}{c}-0.131^{* * *} \\
(0.011)\end{array}$ & $\begin{array}{c}-0.134^{* * *} \\
(0.011)\end{array}$ \\
\hline Observations & 190 & 190 & 190 & 190 & 190 & 190 & 190 \\
\hline F test & 0.984 & 0.891 & 0.882 & 0.675 & 0.827 & 0.917 & 0.751 \\
\hline F prob & 0.401 & 0.447 & 0.451 & 0.670 & 0.551 & 0.483 & 0.662 \\
\hline $\mathrm{R} 2$ & 0.02 & 0.01 & 0.02 & 0.03 & 0.03 & 0.03 & 0.04 \\
\hline
\end{tabular}

Notes: explanatory variables are in log-differences; the China stock index is the Shanghai stock market index. T-stats reported in parenthesis below coefficients and computed based on HAC standard errors. $* * * p<0.01,{ }^{* *} p<0.05,{ }^{*} p<0.1$ 
Table B.5: Estimates from equation Equation (2.4) at daily frequency at daily frequency

\begin{tabular}{|c|c|c|c|c|c|c|c|}
\hline $\begin{array}{l}\text { Dep. variable } \\
\text { 3-T Index (lev.) }\end{array}$ & $\begin{array}{l}\text { Model } \\
(1)\end{array}$ & $\begin{array}{l}\text { Model } \\
(2)\end{array}$ & $\begin{array}{l}\text { Model } \\
(3)\end{array}$ & $\begin{array}{l}\text { Model } \\
(4)\end{array}$ & $\begin{array}{l}\text { Model } \\
(5)\end{array}$ & $\begin{array}{l}\text { Model } \\
(6)\end{array}$ & $\begin{array}{l}\text { Model } \\
(7)\end{array}$ \\
\hline$\Delta \bar{l}_{\Delta S P 500_{t}}$ & $\begin{array}{c}2.900 \\
(4.387)\end{array}$ & & & $\begin{array}{c}4.173 \\
(4.688)\end{array}$ & $\begin{array}{c}5.763 \\
(3.915)\end{array}$ & & $\begin{array}{c}6.145 \\
(4.179)\end{array}$ \\
\hline$\Delta S P 500_{t-1}$ & $\begin{array}{l}2.213 \\
(3.076)\end{array}$ & & & $\begin{array}{c}2.217 \\
(2.936)\end{array}$ & $\begin{array}{l}3.105 \\
(3.384)\end{array}$ & & $\begin{array}{c}2.761 \\
(3.196)\end{array}$ \\
\hline$\Delta S P 500_{t-2}$ & $\begin{array}{l}1.943 \\
(3.084)\end{array}$ & & & $\begin{array}{c}2.019 \\
(3.370)\end{array}$ & $\begin{array}{l}0.976 \\
(2.536)\end{array}$ & & $\begin{array}{l}1.317 \\
(2.699)\end{array}$ \\
\hline$\Delta S P 500_{t-3}$ & $\begin{array}{l}1.470 \\
(6.894)\end{array}$ & & & $\begin{array}{l}1.906 \\
(7.720)\end{array}$ & $\begin{array}{c}4.930 \\
(8.325)\end{array}$ & & $\begin{array}{c}4.975 \\
(8.720)\end{array}$ \\
\hline$\Delta N E E R_{t}^{U S D}$ & & $\begin{array}{c}12.661 \\
(12.172)\end{array}$ & & $\begin{array}{c}17.702 \\
(11.921)\end{array}$ & & $\begin{array}{l}-0.689 \\
(8.296)\end{array}$ & $\begin{array}{c}4.551 \\
(9.182)\end{array}$ \\
\hline$\Delta N E E R_{t-1}^{U S D}$ & & $\begin{array}{l}-10.890 \\
(12.308)\end{array}$ & & $\begin{array}{c}-6.087 \\
(13.732)\end{array}$ & & $\begin{array}{c}-9.268 \\
(10.613)\end{array}$ & $\begin{array}{c}-3.904 \\
(11.999)\end{array}$ \\
\hline$\Delta N E E R_{t-2}^{U S D}$ & & $\begin{array}{c}3.355 \\
(7.672)\end{array}$ & & $\begin{array}{c}6.481 \\
(9.856)\end{array}$ & & $\begin{array}{c}3.228 \\
(10.034)\end{array}$ & $\begin{array}{c}6.965 \\
(11.592)\end{array}$ \\
\hline$\Delta N E E R_{t-3}^{U S D}$ & & $\begin{array}{c}0.014 \\
(10.158)\end{array}$ & & $\begin{array}{c}0.519 \\
(9.254)\end{array}$ & & $\begin{array}{c}-3.561 \\
(14.232)\end{array}$ & $\begin{array}{c}-2.032 \\
(11.313)\end{array}$ \\
\hline$\Delta$ Stock $_{t}^{C H N}$ & & & $\begin{array}{r}-11.422 \\
(9.092)\end{array}$ & & $\begin{array}{l}-13.507 \\
(10.342)\end{array}$ & $\begin{array}{c}-11.453 \\
(9.110)\end{array}$ & $\begin{array}{l}-13.126 \\
(10.392)\end{array}$ \\
\hline$\Delta$ Stock $_{t-1}^{C H N}$ & & & $\begin{array}{c}1.411 \\
(3.675)\end{array}$ & & $\begin{array}{c}0.720 \\
(3.766)\end{array}$ & $\begin{array}{c}0.943 \\
(3.789)\end{array}$ & $\begin{array}{c}0.487 \\
(3.720)\end{array}$ \\
\hline$\Delta$ Stock $_{t-2}^{C H N}$ & & & $\begin{array}{l}-2.260 \\
(3.458)\end{array}$ & & $\begin{array}{l}-4.311 \\
(2.875)\end{array}$ & $\begin{array}{l}-2.195 \\
(4.020)\end{array}$ & $\begin{array}{l}-3.709 \\
(3.301)\end{array}$ \\
\hline$\Delta S t o c k_{t-3}^{C H N}$ & & & $\begin{array}{l}-1.322 \\
(2.180)\end{array}$ & & $\begin{array}{l}-2.656 \\
(2.781)\end{array}$ & $\begin{array}{l}-1.577 \\
(2.394)\end{array}$ & $\begin{array}{l}-2.858 \\
(3.028)\end{array}$ \\
\hline Constant & $\begin{array}{c}-0.368^{* * *} \\
(0.040)\end{array}$ & $\begin{array}{c}-0.363^{* * *} \\
(0.038)\end{array}$ & $\begin{array}{c}-0.363^{* * *} \\
(0.038)\end{array}$ & $\begin{array}{c}-0.364^{* * *} \\
(0.037)\end{array}$ & $\begin{array}{c}-0.357^{* * *} \\
(0.033)\end{array}$ & $\begin{array}{c}-0.358^{* * * *} \\
(0.034)\end{array}$ & $\begin{array}{c}-0.354^{* * *} \\
(0.031)\end{array}$ \\
\hline Observations & 158 & 158 & 158 & 158 & 158 & 158 & 158 \\
\hline F test & 0.458 & 0.476 & 1.274 & 0.557 & 0.942 & 0.655 & 0.656 \\
\hline F prob & 0.712 & 0.699 & 0.285 & 0.764 & 0.466 & 0.686 & 0.747 \\
\hline$R^{2}$ & 0.00 & 0.00 & 3.13 & 0.00 & 2.78 & 0.88 & 0.37 \\
\hline
\end{tabular}

Notes: explanatory variables are in log-differences; the China stock index is the Shanghai stock market index. T-stats reported in parenthesis below coefficients and computed based on HAC standard errors. *** $p<0.01,{ }^{* *} p<0.05,{ }^{*} p<0.1$ 